\title{
The Influence of Climate Factors, Meteorological Conditions, and Boundary-Layer Structure on Severe Haze Pollution in the Beijing-Tianjin-Hebei Region during January 2013
}

\author{
Lili Wang, ${ }^{1}$ Nan Zhang, ${ }^{2}$ Zirui Liu,, ${ }^{1}$ Yang Sun, ${ }^{1}$ Dongsheng Ji, ${ }^{1}$ and Yuesi Wang ${ }^{1}$ \\ ${ }^{1}$ LAPC, Institute of Atmospheric Physics, Chinese Academy of Sciences, Beijing 100029, China \\ ${ }^{2}$ Hebei Province Meteorological Observatory, Shijiazhuang 050022, China \\ Correspondence should be addressed to Yuesi Wang; wys@mail.iap.ac.cn
}

Received 18 July 2014; Accepted 13 October 2014; Published 17 November 2014

Academic Editor: Hiren Jethva

Copyright (C) 2014 Lili Wang et al. This is an open access article distributed under the Creative Commons Attribution License, which permits unrestricted use, distribution, and reproduction in any medium, provided the original work is properly cited.

\begin{abstract}
The air-pollution episodes in China in January 2013 were the most hazardous in the Beijing-Tianjin-Hebei (BTH) region. $\mathrm{PM}_{2.5}$, $\mathrm{AOD}$, and long-term visibility data, along with various climate and meteorological factors and the boundary-layer structure, were used to investigate the cause of the heavy-haze pollution events in January 2013. The result suggests that unfavorable diffusion conditions (weak surface winds and high humidity) and high primary-pollutant emissions have induced heavy-haze pollution in the BTH region over the past two decades. A sudden stratospheric warming (SSW), weak East Asian winter monsoon, a weak Siberian High, weak meridional circulation, southerly wind anomalies in the lower troposphere, and abnormally weak surface winds and high humidity were responsible for the severe haze pollution events, rather than an abrupt increase in emissions. Heavy/severe haze pollution is associated with orographic wind convergence zones along the Taihang and Yanshan Mountains, slight winds $(1.7 \sim 2.1 \mathrm{~m} / \mathrm{s})$, and high humidity (70\% 90\%), which limits the diffusion of pollutants and facilitates the hygroscopic growth of aerosols. Recirculation and regional transport, along with the poorest diffusion conditions and favorable conditions for hygroscopic growth of aerosols and secondary transformation under the high emission, led to explosive growth and the record high hourly average concentration of $\mathrm{PM}_{2.5}$ in Beijing.
\end{abstract}

\section{Introduction}

Haze pollution in China has increased over the past three decades, particularly in city clusters, as a result of the rapidly developing economy, expanding anthropogenic activities and urbanization $[1,2]$. The Beijing-Tianjin-Hebei (BTH) city cluster located in the North China Plain, which includes two megacities (Beijing and Tianjin) and Hebei province, has one of the largest populations (Figure 1(a)) and the third largest gross domestic product in China [3-5]. In recent years, large-scale regional haze pollution characterized by high concentrations of $\mathrm{PM}_{2.5}$ (particulate matter with aerodynamic diameters $\leq 2.5 \mu \mathrm{m}$ ) has frequently occurred [6-8], and the levels of $\mathrm{PM}_{2.5}$ continue to frequently exceed the national ambient air quality standards of China [9]; as a result, serious environmental, climatic, and health problems are rampant $[10,11]$.
A relatively high level of $\mathrm{PM}_{2.5}$ is usually associated with the close proximity of high precursor emissions [12]. In addition, weather/climate features play a significant role in air quality through a complex combination of processes and influences, such as emissions, transport, chemical transformations, and wet or dry removal processes. Severe pollution episodes in the urban environment mainly result from unfavorable air dispersion related to weather conditions $[13,14]$. Researchers have investigated that the effects of climate change on haze/ $\mathrm{PM}_{2.5}$ pollution and revealed that a significant contribution came from the weakening monsoon circulation in past decades, trapping more pollutants over Eastern China $[15,16]$. On the synoptic scale, high pressure and successive low pressure systems are associated with the formation of air pollution, and pressure systems with strong gradients lead to the decrease of the air-pollution index (API) over North China [17]. Moreover, the BTH region is 


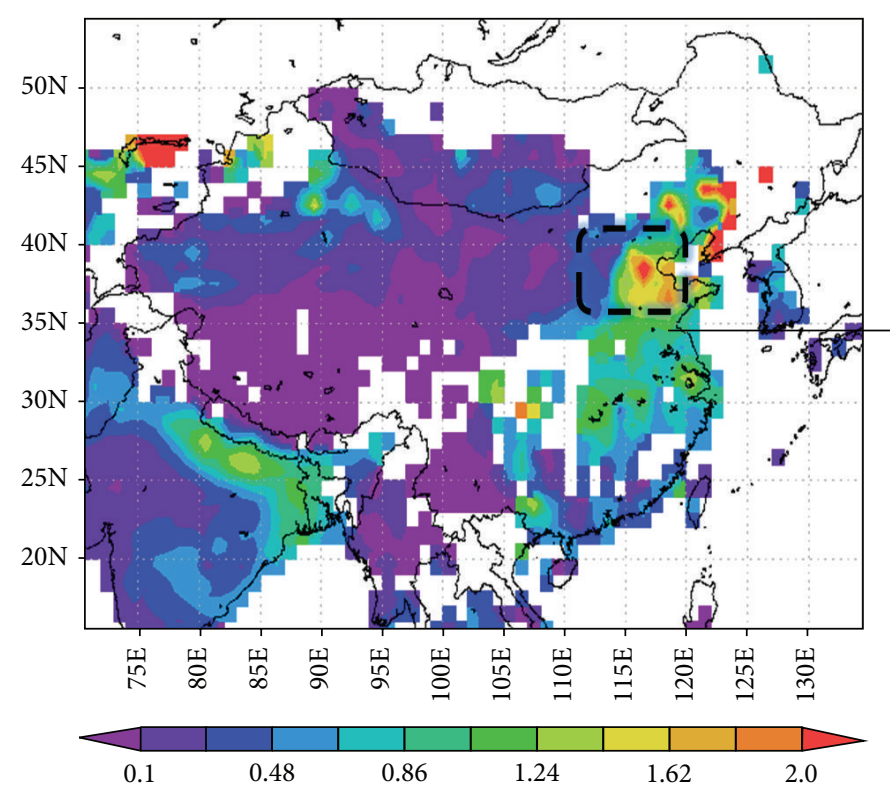

(a)

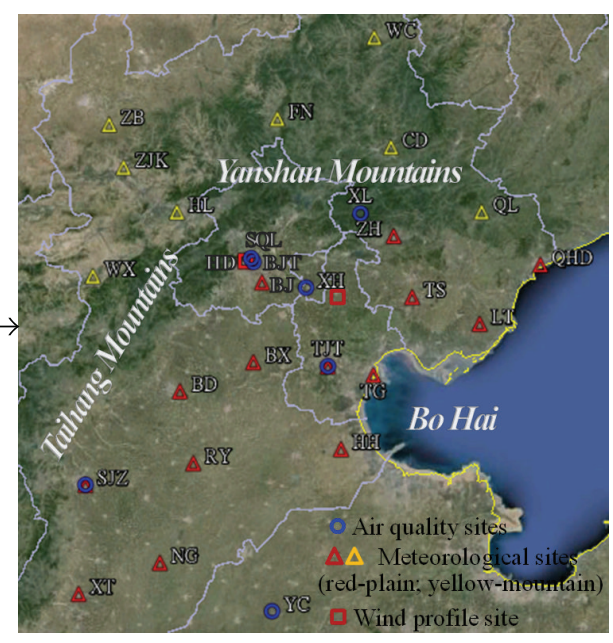

(b)

Figure 1: (a) Monthly mean deep-blue AOD at $550 \mathrm{~nm}$ wavelength in January 2013 over China derived from Aqua MODIS $1^{\circ} \times 1^{\circ}$ level-3 daily products. (b) Topographic map and the locations of meteorological and air quality measurement sites over the BTH region.

surrounded by mountains in the north and west directions and by Bohai Sea in the east direction (Figure 1(b)). Unique local topographic factor, together with stagnant weather with weak wind and temperature inversion, and regional transported contribution by south wind can induce heavy air pollution [18-20]. Due to the combustion of coal for heating and the unfavorable dispersion attributable to geographical and meteorological conditions, haze pollution in winter over the BTH region is more serious $[21,22]$. The governments, especially the Beijing municipal government, have produced a series of emission reduction measures to control air pollution $[4,23]$, such as changes of industrial structure and improved energy efficiency, the use of clean energy and preferred use of clean coal and gases, vehicle limitation measures, and implementation of advanced environmental standards. However, the pollution levels are still very high all the year round. Hazardous air-pollution episodes occurred in January 2013 and affected the BTH region of China the most (Figure 1(a)); thus, this event has attracted extensive attention $[6,19,24]$.

Scientists have investigated the effect of regional transport and local accumulation during stagnant weather and the secondary formation of particulate on severe regional $\mathrm{PM}_{2.5}$ pollution events in January $2013[6,19,25,26]$. Notably, the emission source did not increase rapidly in January 2013. Zheng et al. elaborated that [27] the changes of monthly averaged emissions in January over the Beijing-Tianjin-Hebei region were increased in rates, that is, $2.1 \%, 1.5 \%$, and $2.5 \%$ for primary $\mathrm{PM} 2.5, \mathrm{SO}_{2}$, and $\mathrm{NO}_{x}$, respectively, compared with emissions in January 2012, but they were still not significant compared to the changes in pollutant concentrations and the weather/climate elements was principally responsible for these heavy pollution episodes. Zhang et al. [28] pointed out that the weakened surface winds, the anomalous southerly winds in the middle and lower troposphere, and the anomalous inversion were associated with the strong haze/fog event in Eastern China by diagnosing both its atmospheric background fields and daily evolution in January 2013. However, few studies have explored the characteristics and formation of heavy $\mathrm{PM}_{2.5}$ pollution in regard to climate factors, meteorological conditions, and boundary-layer structure over the $\mathrm{BTH}$ region; these factors will be important for implementing effective control measures of air pollution on the regional scale.

In this study, $\mathrm{PM}_{2.5}$, $\mathrm{AOD}$, and long-term visibility data, along with various climate and meteorological factors and the boundary-layer structure, were used to investigate the cause of serious haze pollution events in January 2013 and to determine the relevant meteorological features during the most hazardous $\mathrm{PM}_{2.5}$ pollution episode (10-14 January, 2013).

\section{Measurement Sites and Data Descriptions}

2.1. Sites and $P M_{2.5}$ Measurements. The locations of the 22 meteorological observation sites and 7 air quality sites selected for this study over the BTH region are displayed in Figure 1(b). Detailed information on the air quality sites is given in Table 1. Fourteen meteorological sites are located in the plains area, and 8 sites are located in the mountainous regions. Seven air quality sites (including 4 urban sites: Beijing Tower (BJT), Shuangqing Lu (SQL), Tianjin (TJ), and Shijiazhuang (SJZ); 1 suburban site: Xianghe $(\mathrm{XH})$; 1 rural site: Yucheng (YC); and 1 regional background site: Xinglong (XL)) are local in the southern 
TABLE 1: Locations of air quality sites over the BTH region.

\begin{tabular}{|c|c|c|c|c|}
\hline Station name & Station type & Latitude $\left({ }^{\circ} \mathrm{N}\right)$ & Longitude $\left({ }^{\circ} \mathrm{E}\right)$ & Altitude (m) \\
\hline Beijing Tower (BJT) & Megacity & 116.37 & 39.97 & 44 \\
\hline Shuangqing Lu (SQL) & Megacity & 116.33 & 39.99 & 45 \\
\hline Tianjin (TJ) & Megacity & 117.21 & 39.08 & 20 \\
\hline Shijiazhuang (SJZ) & Megacity & 114.53 & 38.03 & 70 \\
\hline Xianghe (XH) & Suburban & 116.96 & 39.75 & 9 \\
\hline Yucheng (YC) & Country & 116.37 & 36.67 & 37 \\
\hline Xinglong (XL) & Regional background & 117.58 & 40.39 & 960 \\
\hline
\end{tabular}

plain, where the air pollution is most severe. Air quality monitoring was conducted via an observation network established by the Institute of Atmospheric Physics (IAP), Chinese Academy of Sciences (CAS). The online measurement of the mass concentration of $\mathrm{PM}_{2.5}$ or $\mathrm{PM}_{10}$ was obtained by a Tapered Element Oscillating Microbalance (Model 1400A, R\&P), and data were collected every five minutes. The instrument's measuring principle coincides with that of the US Environmental Protection Agency (EPA) (http://www.epa.gov/ttnamtil/inorg.html). The hourly average concentrations were calculated with the $5 \mathrm{~min}$ data; and daily average concentrations were acquired based on $1 \mathrm{~h}$ data. Monthly mean deep-blue AOD at $550 \mathrm{~nm}$ wavelength in January 2013 over China derived from Aqua MODIS $1^{\circ} \times$ $1^{\circ}$ level-3 daily products was shown in Figure 1(a), which revealed that the BTJ region was the most pollution area in China.

The air-pollution index (AQI) is a quantitative measure describing air-pollution levels in China based on the conversion of air-pollution data, mainly $\mathrm{PM}_{10}, \mathrm{PM}_{2.5}, \mathrm{SO}_{2}, \mathrm{NO}_{2}$, $\mathrm{CO}$, and $\mathrm{O}_{3}$ concentrations, into a single value ranging from 0 to 500. The API is divided into six ranks representing different air quality levels with respect to their impacts on human health. The first and second air quality levels (I: AQI $=0-50$ and II: AQI $=51-100)$ represent good air quality and no human-health risk. The third and fourth levels (III: AQI = 101-150 and IV: AQI = 151-200) indicate light pollution affecting human health to some degree. The fifth and sixth levels (V: AQI $=201-300$ and VI: AQI > 300) denote heavy pollution and serious effects on human health. The AQI of the city is defined by the maximum subindex among all the six pollutants. In January 2013, the major pollutant was $\mathrm{PM}_{2.5}$; thus, air quality levels were divided by air quality index (AQI) according to $\mathrm{PM}_{2.5}$ concentrations. The corresponding concentration at the breakpoint in different air quality levels is $35,75,115,150$, and $250 \mu \mathrm{g} / \mathrm{m}^{3}$, respectively.

2.2. Meteorological Data. The meteorological data (daily average and monthly average) at the plains sites and mountainous sites, the visibility and relative humidity (RH) at 14:00 LST at six plains sites since 1980 (Figures 1(b) and 2 ), and synoptic maps were obtained from the National Meteorological Information Center and China Meteorological Administration. The visibility and RH at 14:00 LST from
1960 to 1979 were from NOAA's National Climatic Data Center (NCDC); data was unavailable during 1965-1972. In this work, haze events were defined as days with the visibility (at 14:00 LST) $<10 \mathrm{~km}$ and the $\mathrm{RH}<90 \%$, excluding days with fog, precipitation, dust storms, smoke, snow storms, and so forth. This definition is more appropriate for quantifying haze days compared with the definition using daily mean meteorological data in the BTH area $[2,21,29]$. The hourly meteorological data, wind direction, wind speed, and $\mathrm{RH}$ are measured with automatic weather stations (AWSs) in BJ, TJ, SJZ, XH, YC, and XL. The wind parameters are observed at a $10 \mathrm{~m}$ height, and the moisture information is collected at $1.5 \mathrm{~m}$ height. In addition, 370 AWSs with wind data and humidity information within $36^{\circ}-42.5^{\circ} \mathrm{N}$ and $113.5^{\circ}-120^{\circ} \mathrm{E}$ are used to obtain the gridded hourly surface-wind field and relative humidity using the Grid Analysis and Display System (GrADS) software. Gridded surface RH and wind data from the National Centers for Environmental Prediction (NCEP)/National Center for Atmospheric Research (NCAR) final global forecast system (FNL) reanalysis dataset $\left(1^{\circ}\right.$ horizontal resolution) were also used to reveal the characteristic wind field and moisture distribution that have led to haze events in the BTH region. The wind directions in this paper are referred to as the directions the winds are coming from. In the Beijing urban area and Tianjin suburban area, the wind profiles with a temporal resolution of 6 min were observed with a boundary-layer wind-profile Lidar (Figure 1(b)). The radiosonde data at the Beijing meteorological station (54511) were used to analyze the vertical structure of the temperature and humidity.

Zonal circulation index for Asia (IZ), meridional circulation index for Asia (IM), East Asian winter monsoon (EAWM) intensity index, Siberian High (SH) intensity index, $1000 \mathrm{hPa}$ wind anomaly, and integrated moisture flux anomaly were provided by National Climate Center (http://cmdp.ncc.cma.gov.cn/cn/index.htm). The anomalies are calculated from their departures from 1981-2010 mean values. NCEP GDAS-CPC zonal temperature anomaly downloaded from http://www.cpc.ncep.noaa.gov/products/stratosphere/strat-trop/ was used to analyze a sudden stratospheric warming (SSW).

2.3. Satellite Data. Moderate resolution imaging spectroradiometer (MODIS) onboard the Terra and Aqua 


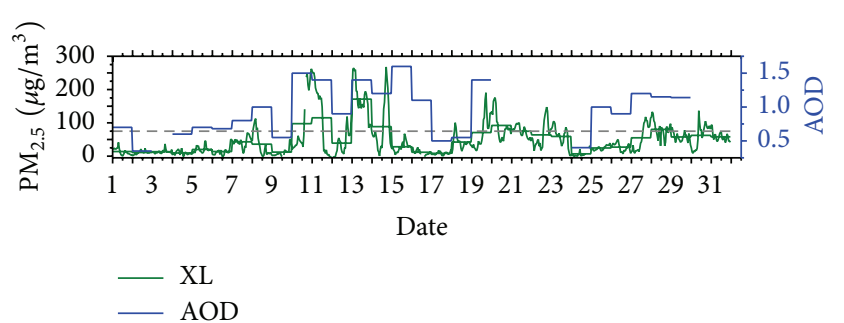

(a)

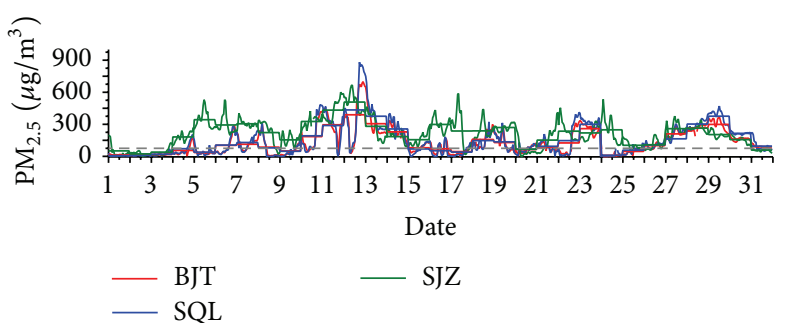

(b)

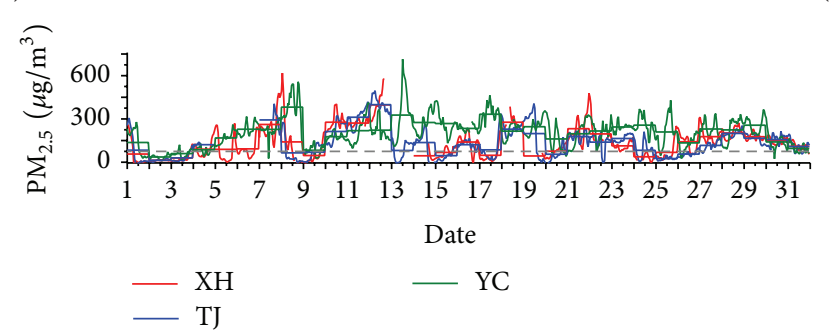

(c)

FIGURE 2: Variation of hourly average (sawtooth lines) and daily average (step lines) concentrations of $\mathrm{PM}_{2.5}$ in different sites and regional average AOD in January 2013 over the BTH region. Dashed lines show the Grade II National Ambient Air Quality Standard.

satellites provides a high spatial resolution and near daily global coverage aerosol optical depth (AOD) data [30, 31]. The MODIS AOD products (MOD04/MYD04) over land comprise two datasets: dark-target AOD data and deep-blue AOD data (http://modis-atmos.gsfc.nasa.gov/ MOD04_L2/index.html). The former is applicable to dark surfaces, and the latter is applicable to bright desert surfaces [32-35]; these datasets have been released as MODIS aerosol products, Collection 051, with spatial resolutions of $10 \mathrm{~km} \times 10 \mathrm{~km}$ or $1^{\circ} \times 1^{\circ}$ (http://modis-atmos .gsfc.nasa.gov/MOD04_L2/atbd.html). Because less vegetation cover exists in winter over the $\mathrm{BTH}$ region, the deep-blue AOD data at $550 \mathrm{~nm}$ from MYD04_L3 C051 were used. Aqua MODIS $1^{\circ} \times 1^{\circ}$ level-3 daily products were averaged over the region $35^{\circ}-43^{\circ} \mathrm{N}$ and $112^{\circ}-120^{\circ} \mathrm{E}$ in January from 2004 to 2013.

\section{Results and Discussion}

3.1. Distributions of $P M_{2.5}$ and AOD in the BTH Region. Variations in the hourly average and daily average concentrations of $\mathrm{PM}_{2.5}$ at different sites and the regional average AOD in January 2013 over the BTH region are described in Figure 2. The most polluted site was SJZ, with a monthly average value of $\sim 214 \mu \mathrm{g} / \mathrm{m}^{3}$; and the second most polluted site was $\mathrm{YC}$, with a value of $\sim 203 \mu \mathrm{g} / \mathrm{m}^{3}$. BJT, SQL, TJ, and XH were moderately polluted, with values of $\sim 132-143 \mu \mathrm{g} / \mathrm{m}^{3}$. The least polluted site was XL, with a value of $\sim 49 \mu \mathrm{g} / \mathrm{m}^{3}$. The YC site had a very high $\mathrm{PM}_{2.5}$ level, although it was a rural site, which indicated the influence of regional transport. Overall, the variation of $\mathrm{PM}_{2.5}$ concentrations at the different sites showed regional characteristics and periodic changes. Except $\mathrm{XL}$ (a regional background site), the $\mathrm{PM}_{2.5}$ concentrations far exceeded the Grade II National Ambient Air Quality
Standard (75 $\mu \mathrm{g} / \mathrm{m}^{3}$, GB3095-2012). The frequencies of the regional air quality at levels I and II, III and IV, and V and VI (the regional air quality level was based on the level occurring at a minimum of 4 sites) were 3 days, 13 days, and 15 days, respectively, and the corresponding regional mean $\mathrm{PM}_{2.5}$ concentrations were $36 \pm 33 \mu \mathrm{g} / \mathrm{m}^{3}, 115 \pm 83 \mu \mathrm{g} / \mathrm{m}^{3}$, and $224 \pm 88 \mu \mathrm{g} / \mathrm{m}^{3}$, respectively. The regional average AOD was also very high, with a range from 0.35 to 1.5 . The regional background site (XL) had 6 days that exceeded the Grade II standard. Two consecutive and regionally severe haze episodes were significant (10-14 and 26-30) but with different characteristics, that is, "explosive growth" and "sustained growth" of $\mathrm{PM}_{2.5}$, respectively. However, the highest regional mean concentration $\left(\mathrm{PM}_{2.5}\right.$ of $\sim 250 \mu \mathrm{g} / \mathrm{m}^{3}$ and an AOD of 1.3) was observed during 10-14; meanwhile, the highest hourly concentration $\left(881 \mu \mathrm{g} / \mathrm{m}^{3}\right)$ was found at the SQL site in Beijing.

3.2. Effects of Climatic Factors on Haze Pollution. Several datasets were used to analyze the effects of climatic factors on haze pollution over the BTH region (Figure 3 ). Interannual variations were calculated for precipitation, wind speed, temperature, relative humidity, and sunshine hours' anomalies in the plains and mountainous sites. Temperature, depression of the dew point, and wind speed at $850 \mathrm{hPa}$ level anomalies at BJ and XT were analyzed. IZ and IM for Asia were also displayed. Additionally, the occurrences of haze at five urban sites and a suburban site, the mean visibility for all days and haze days, and the mean AOD over the $\mathrm{BTH}$ region were computed for January. The precipitation presented an irregular fluctuation. The change in the averaged surface wind speed and sunshine hours over all the stations, particularly over the plains stations, showed a rapid decrease from 1960 to around 1990, whereas the wind speed remained constant 


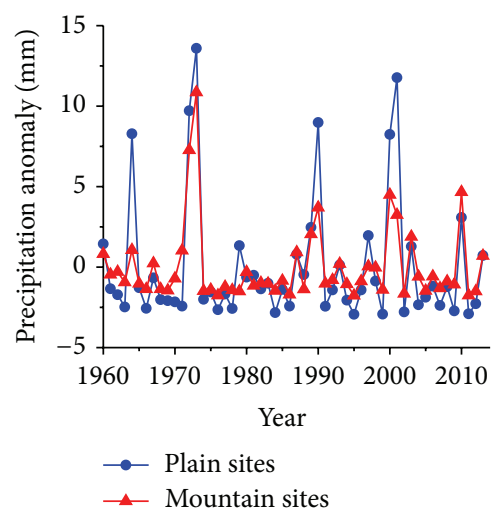

(a)

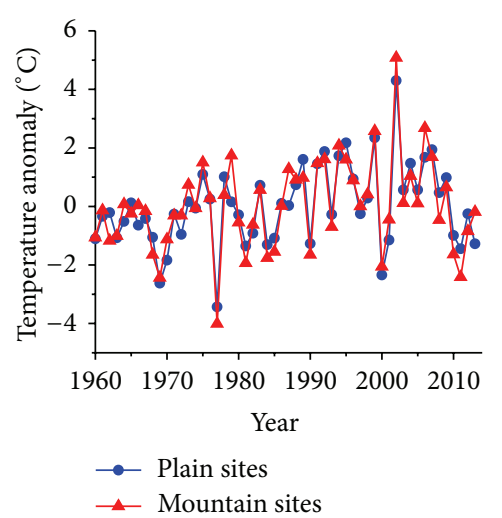

(c)

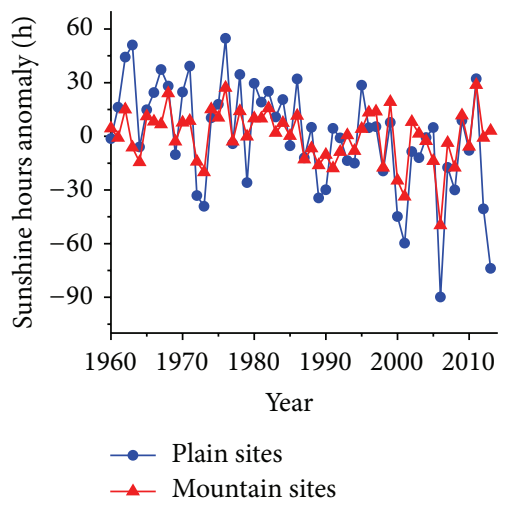

(e)

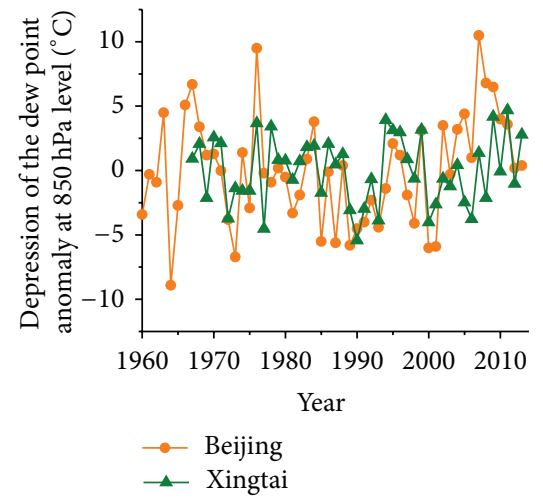

(g)

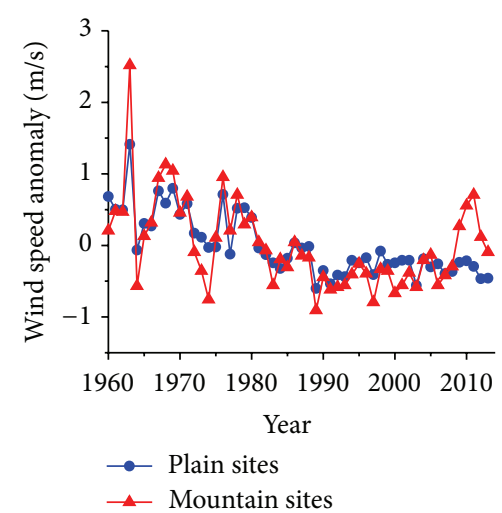

(b)

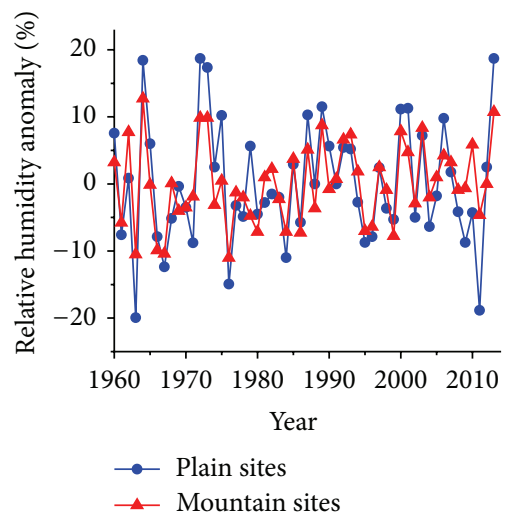

(d)

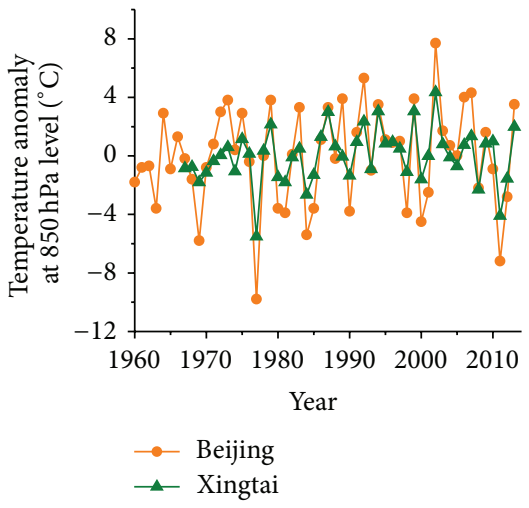

(f)

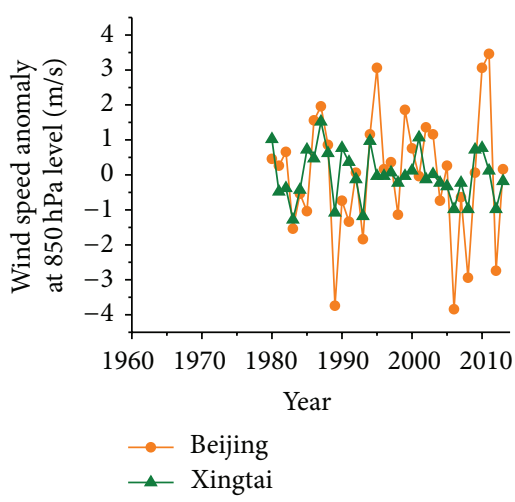

(h)

Figure 3: Continued. 


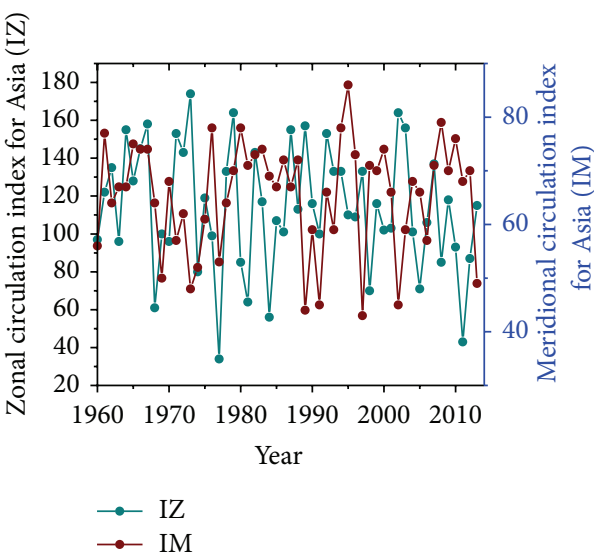

(i)

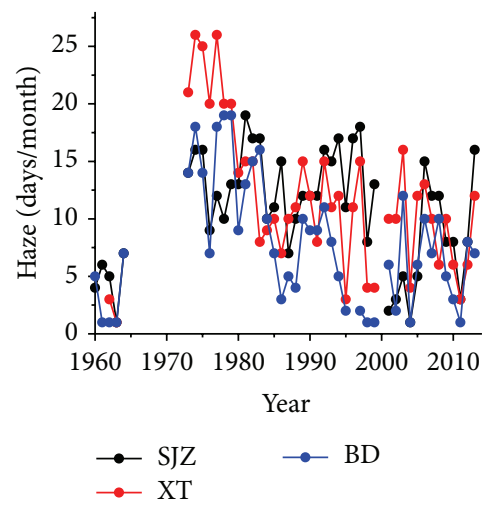

(j)

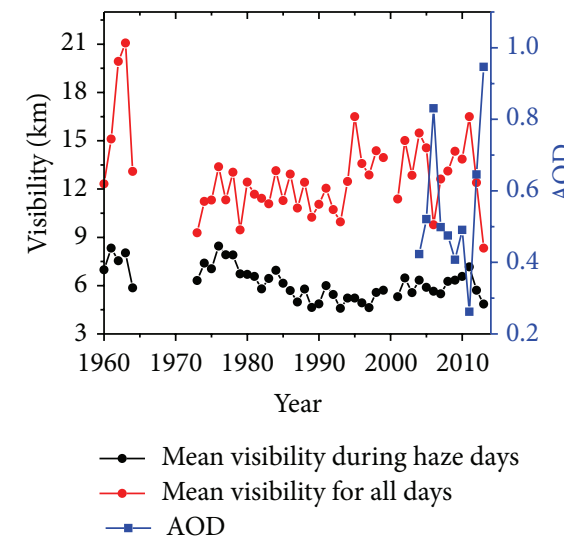

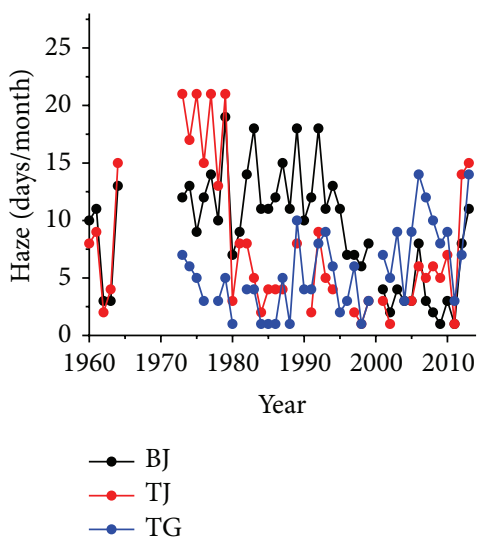

$(\mathrm{k})$

(1)

Figure 3: Interannual variations of (a) (e) precipitation, wind speed, temperature, relative humidity, and sunshine hours' anomalies for the plains and mountainous sites, respectively; (f) (h) temperature, depression of the dew point, and wind speed at $850 \mathrm{hPa}$ level anomalies at Beijing (BJ) and Xingtai (XT), respectively; (i) IZ and IM; (j) (k) the occurrences of haze at five urban sites (BJ, TJ, SJZ, BD, and XT) and a suburban site (TG); (l) mean visibility for all days and haze days and mean AOD over the BTH region in January. The climatology is calculated based on the mean in January from 1960 to 2013.

in the plains sites and slightly increased in the mountainous sites; the sunshine hours exhibited a sustained decline in the plains sites and a steady oscillation in the mountain sites from 1990 to 2013; this trend is consistent with that found in many areas in China [36, 37]. Therefore, increasingly poor dispersion conditions superimposed with high aerosol loadings contributed to regional dimming. The temperature and $\mathrm{RH}$ increased over time as a result of industrial activities and urbanization. High moisture facilitates the hygroscopic growth of aerosols, which increases aerosol mass concentrations and extinction; these conditions lead to low-visibility events. However, the trends in the temperature, moisture, and wind speed at the $850 \mathrm{hPa}$ level were not significant. IZ and IM for Asia changed dramatically over different years, and the amplitude of the variation increased. A weak negative correlation existed between the mean visibility and IZ, but a significantly positive correlation existed between the mean visibility and IM; thus good dispersion conditions resulted in high visibility when IM was high. The meridional circulation was strong, which facilitates ventilation due to the frequent exchange of southern and northern air masses.

On average, low-visibility and haze days at the urban sites were less frequent before the early 1970s; then the frequency increased and remained a constant high value before 1998 due to the rapid economic development starting in the late 1970s. Afterward, a sudden decrease in the frequency occurred, while the amplitude of the variation changed drastically. At the suburban site, an increase in haze days occurred from the early 2000s (when this region became a special economic zone) to the present, indicating that the timing of economic development plays an important role in haze pollution. Surprisingly, the interannual variation in the mean visibility during the haze days showed a significant decrease, which indicated that the primary type of haze changed from slight haze $(5-10 \mathrm{~km})$ to severe or serious haze $(<5 \mathrm{~km})$ since the beginning of the 1990s. The results suggest that unfavorable diffusion conditions (weak surface winds and high surface humidity) combined with high primary-pollutant emissions 


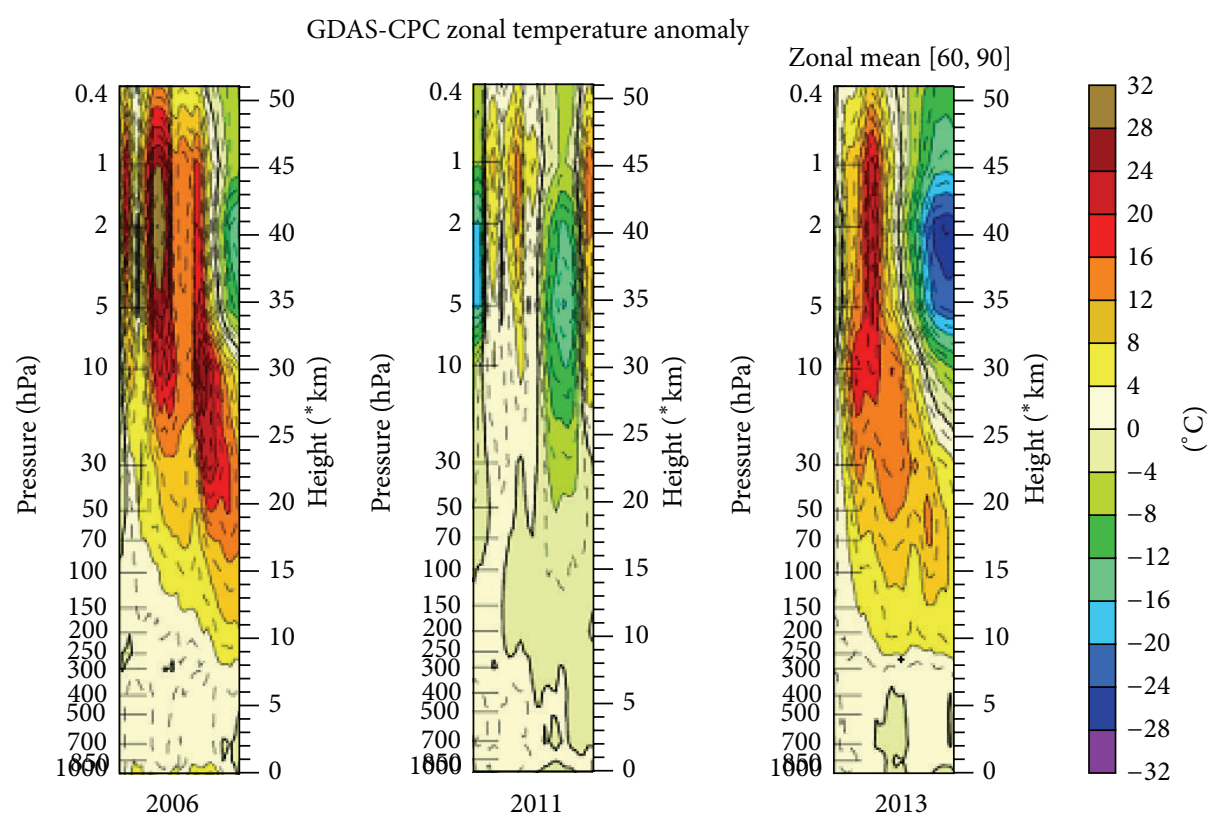

FIGURE 4: NCEP GDAS-CPC zonal mean time series of temperature for January of 2006, 2011, and 2013.

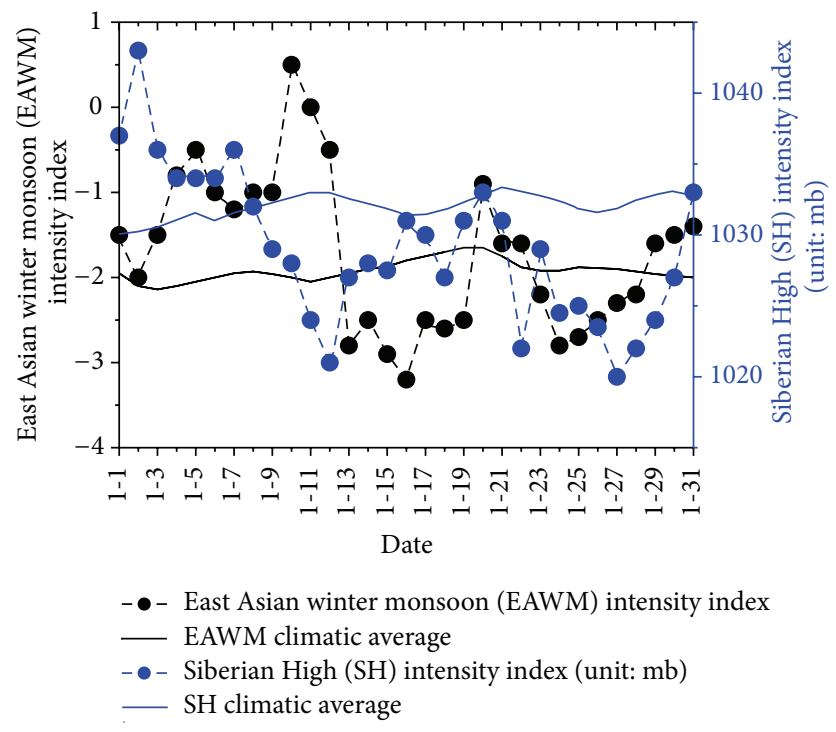

FIGURE 5: Time series of EAWM intensity index and SH intensity index, along with their climatic averages.

[2] have induced very heavy-haze pollution in the BTH region over the past two decades.

Under the influences of abnormally weak wind, high humidity near the ground, high upper-air temperature, low surface temperatures, weak meridional circulations, haze pollution levels, and AOD loadings were very strong in the years 2006 and 2013, whereas the air quality in 2011 was rather good due to the opposite meteorological conditions. In addition, a sudden stratospheric warming (SSW) (Figure 4) kept the stratosphere anomalously warm in 2006 and 2013 compared with the zonal temperature anomaly distribution in 2011 . This phenomenon can contribute to the reversed direction of the westerly winds of the polar vortex; these conditions weaken the polar vortex. In addition, the increasing temperature in high-latitude regions may influence the circulation and contribute to a weaker pressure gradient force. As shown in Figure 5, during the course of its rotation and collapse, a weakened polar vortex in northern Asia was associated with a weak EAWM intensity index and SH intensity index; the monsoon occasionally transported weak cold air to the eastern regions of China. When cold air transport was weak, Eastern China was under the influence of southerly wind anomalies in the lower troposphere (Figure 6(a)) and abnormal water vapor divergence (less precipitation) (Figure 6(b)), which resulted in reduced wind velocity and increased air pollution.

3.3. Influence of Meteorological Conditions on $P M_{2.5}$ Concentrations in January 2013. The concentration level of $\mathrm{PM}_{2.5}$ is dependent on wind and relative humidity; wind is related to dispersion and the transport of air pollution, while $\mathrm{RH}$ is associated with the hygroscopicity and scattering of particles. The distributions of the average surface $\mathrm{RH}$ and wind field for different periods in January 2013 are depicted in Figure 7. Wind speeds in the plains area of the BTH region are weaker over North China, and the lowest values are found in the cities near the Yanshan and Taihang Mountains because of the orography and surface roughness in large cities (densely distributed high buildings). A weak southerly wind prevailed over the piedmont plain in the BTH region in January 2013. Moreover, an orographic wind convergence zone was set up along the plain-mountain transition area along the Taihang Mountains, where a concentrated contamination zone was present. Therefore, the highest concentration in SJZ was partly attributed to the convergence zone. In addition, the 


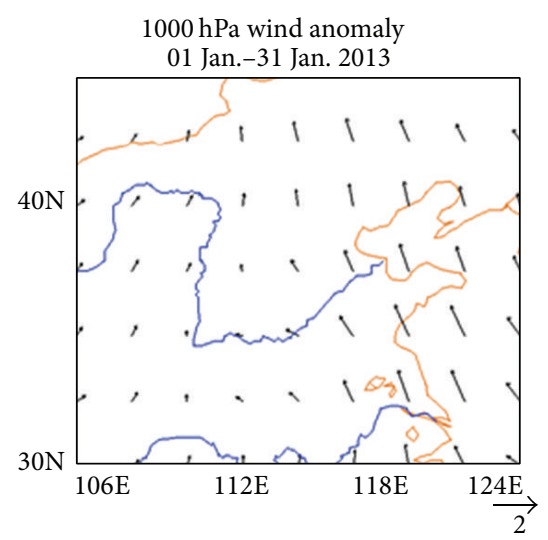

Anomaly integrated moisture flux 01 Jan.-31 Jan. 2013

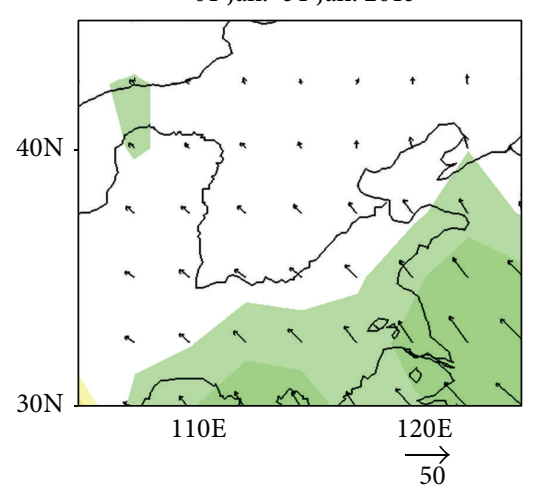

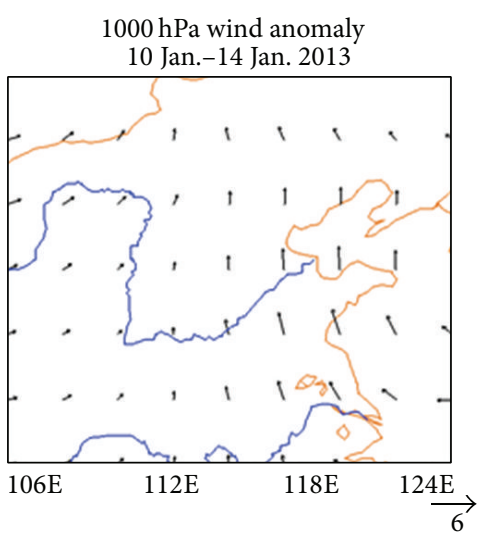

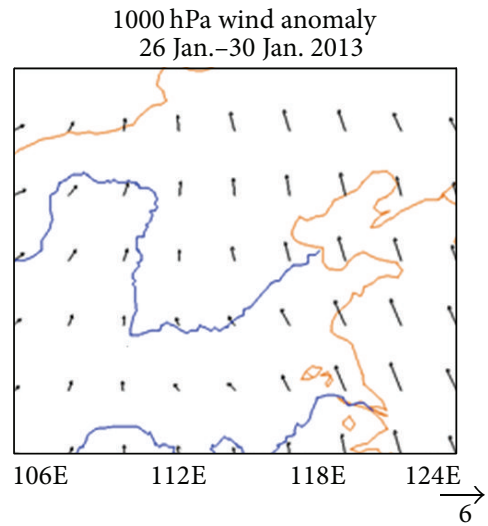

(a)

Anomaly integrated moisture flux 10 Jan.-14 Jan. 2013

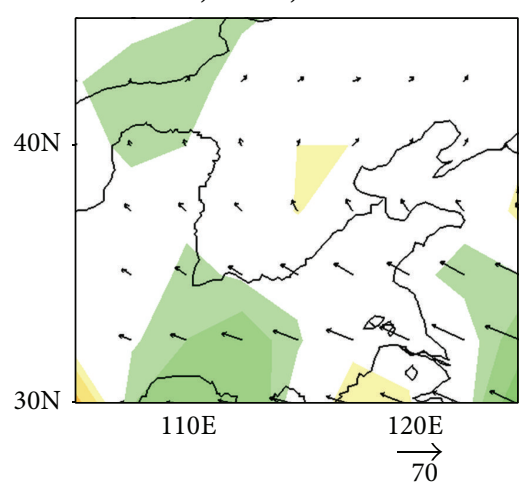

Anomaly integrated moisture flux 26 Jan.-30 Jan. 2013

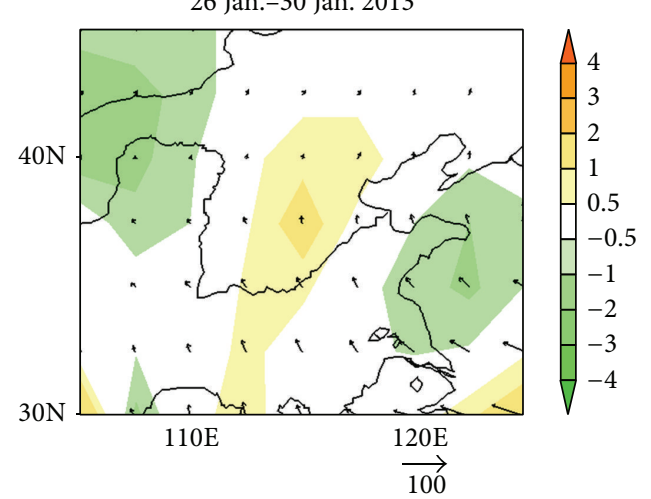

(b)

Figure 6: (a) $1000 \mathrm{hPa}$ wind anomaly (vectors; m/s) (b) integrated moisture flux from 1000 to $300 \mathrm{hPa}$ (vectors; $\mathrm{kg} /(\mathrm{s} \cdot \mathrm{m})$ ) with convergence $(<0)$ and divergence $(>0)$ (shadings; $10^{-5} \mathrm{~kg} /\left(\mathrm{s} \cdot \mathrm{m}^{2}\right)$ ) for different periods during January 2013 using daily and monthly mean NCEP/NCAR reanalysis data with a $2.5^{\circ}$ resolution.

wind convergence zones were located in the north along the Yanshan Mountains during the two heavy-haze pollution episodes. These two orographic wind convergence zones resulted in the pollution accumulation in the piedmont plain and restrained the diffusion of pollutions; as a result, severe regional haze pollution developed. In addition, haze events are strongly influenced by the ambient $\mathrm{RH}$. The $\mathrm{RH}$ values over the plains region of the BTH area were $65 \% \sim 80 \%$ in January, $70 \% \sim 90 \%$ on $10-14$ January, and $80 \%$ 95\% on 26-30 January. Thus, an increasing number of haze events were possibly caused by the hygroscopic growth of aerosols. Because the decreased wind speed and weakened southerly winds resulted in more stable atmospheric conditions and weaker dispersion, more effort should be paid to control emissions and prevent haze events.

Meteorological factors in January 2013 for different air quality levels over the BTH region are summarized in Table 2. Compared with good air quality levels (I and II), the characteristics of the surface meteorological variables during moderate and severe haze pollution episodes in the BTH region were as follows: weaker pressure, higher temperature, particularly in the plains region, higher relative humidity, weak wind (less than $1.7 \sim 2.1 \mathrm{~m} / \mathrm{s}$ ), fewer sunshine hours, and lower visibility. Wind roses, the relationships between the hourly average $\mathrm{PM}_{2.5}$ concentration and wind speed, and wind direction in January at different sites are presented in Figure 8. The lowest wind speed was found in SJZ, which is consistent with the result in Figure 7. The wind speeds associated with southeast to southwest winds were very low at most of the sites, except at YC. The northwest winds were strong in $\mathrm{BJ}$ and $\mathrm{XL}$ but weak at the remaining sites. Southwest wind, northeast wind, and calm winds were dominant. Higher $\mathrm{PM}_{2.5}$ values were associated with weak winds (less than $3 \mathrm{~m} / \mathrm{s}$ ), except at XL and YC sites. At XL site, higher $\mathrm{PM}_{2.5}$ values were associated with strong southwest, south, and north winds; and the $\mathrm{PM}_{2.5}$ concentration at the YC site increased with the elevated wind speed, except for the northeast and southeast winds, which indicated the influence of the regional transport as the surrounding regions have high emissions.

3.4. Influence of Weather Systems, Horizontal Wind Field, and Structures of the Atmospheric Boundary Layer $(A B L)$ on Consecutive and Regionally Severe Haze Episode. The heaviest 


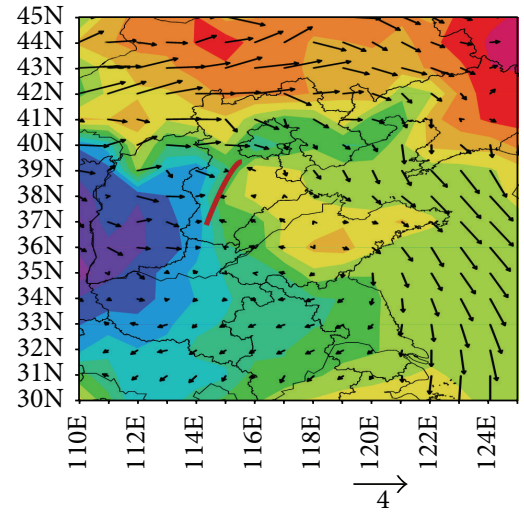

(a)

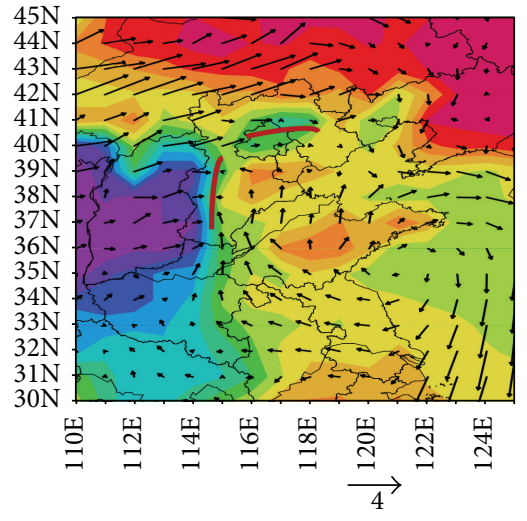

(b)

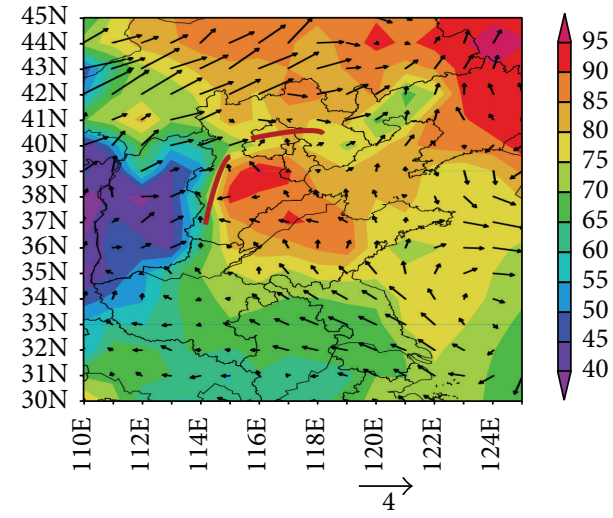

(c)

FIGURE 7: The distributions of the average surface RH (shaded) and wind field (black arrows) from NCEP/NCAR FNL reanalysis data for different periods in January 2013: (a) 1-31, (b) 10-14, and (c) 26-30. Red lines represent the orographic convergence line.

TABLE 2: Summary of meteorological factors in January 2013 in different air quality levels over the BTH region.

\begin{tabular}{|c|c|c|c|c|c|c|c|c|}
\hline & $\begin{array}{l}\text { Air quality } \\
\text { levels }\end{array}$ & & $\begin{array}{c}\text { Pressure } \\
(\mathrm{hPa})\end{array}$ & $\begin{array}{c}\text { Wind speed } \\
(\mathrm{m} / \mathrm{s})\end{array}$ & $\begin{array}{c}\text { Temperature } \\
\left({ }^{\circ} \mathrm{C}\right)\end{array}$ & RH (\%) & $\begin{array}{c}\text { Sunshine hour } \\
\text { (h) }\end{array}$ & $\begin{array}{c}\text { Visibility } \\
(\mathrm{km})\end{array}$ \\
\hline \multirow{6}{*}{ All sites } & \multirow{2}{*}{ I\&II } & Mean & 1002.9 & 3.4 & -11.8 & 41.5 & 7.9 & \\
\hline & & $\mathrm{SD}$ & 46.8 & 2.3 & 5.4 & 11.5 & 0.6 & \\
\hline & \multirow{2}{*}{ III\&IV } & Mean & 997.5 & 2.1 & -7.4 & 64.8 & 5.6 & \\
\hline & & SD & 45.7 & 1.2 & 4.7 & 16.6 & 3.3 & \\
\hline & \multirow{2}{*}{$\mathrm{V} \& \mathrm{VI}$} & Mean & 994.7 & 1.7 & -5.7 & 76 & 3.1 & \\
\hline & & SD & 45.4 & 0.9 & 3.4 & 13.7 & 3.5 & \\
\hline \multirow{6}{*}{ Plain sites } & \multirow{2}{*}{ I\&II } & Mean & 1031.2 & 3.1 & -9 & 40 & 8 & 20.3 \\
\hline & & $\mathrm{SD}$ & 9.6 & 2.3 & 3.2 & 11 & 0.7 & 6.1 \\
\hline & \multirow{2}{*}{ III\&IV } & Mean & 1025.7 & 1.9 & -5.5 & 68.5 & 5.1 & 10.8 \\
\hline & & $\mathrm{SD}$ & 5.6 & 1.1 & 3.1 & 16.3 & 3.3 & 4.9 \\
\hline & \multirow{2}{*}{$\mathrm{V} \& \mathrm{VI}$} & Mean & 1022.8 & 1.8 & -4.2 & 82.1 & 1.4 & 4.3 \\
\hline & & SD & 4.7 & 0.9 & 2 & 11 & 2.5 & 3.3 \\
\hline
\end{tabular}

SD represents standard deviation.

regional haze pollution episode (January 9 to 14) is described in Figure 9. In contrast to other winter regional haze events reported by Zhao et al. [21]; the most significant characteristic of this episode was the "explosive growth" of $\mathrm{PM}_{2.5}$ and $\mathrm{PM}_{10}$ [6] on 12 January in Beijing. Synoptic maps and wind fields (Figure 10), vertical profiles of wind (Figure 11), and temperature/humidity (Figure 12) were used to explore the formation of this heavy pollution from a meteorological perspective. On 10 January, the BTH region was located in the preceding part of low pressure and experienced southerly winds; the weak mixing and reduced dispersion under these conditions led to high levels of aerosol concentrations over the entire region. A north wind arrived north of Beijing due to moving low pressure at 14:00 LST on 11 January, and the particles in Beijing were quickly dispersed. However, the north wind only affected the air pollution in Beijing, and the south winds were still prevalent in the remainder of the region. Shortly afterward, a south wind occupied the entire region, and the $\mathrm{PM}_{2.5}$ concentration in Beijing immediately rebounded due to the recirculation and transport of highconcentration pollutants from the south. Then, because of the combined effect of fast-moving weak low pressure in the north and steadily building high pressure in the south (Figure 10(c)), the winds in Beijing suddenly veered to the north and dispersed the pollutants at 02:00 LST on the 12th; the winds were soon southerly again at 14:00 LST. The pollutants were initially transported from Beijing but later returned. At the same time, the high-concentration pollutants in the south were transported into Beijing. Because the north wind only arrived in Beijing, the $\mathrm{PM}_{2.5}$ concentrations in the remaining areas increased or stayed constant under the prevailing southerly winds. This recirculation and repeated accumulation and transport from the south over a short period were responsible for the explosive growth of the $\mathrm{PM}_{2.5}$ and $\mathrm{PM}_{10}$. A few hours later, east winds prevailed in the region, and the $\mathrm{PM}_{2.5}$ concentrations at most of the sites began to decrease. However, Beijing was the convergence point of the weak southwest wind, southeast wind, and north 

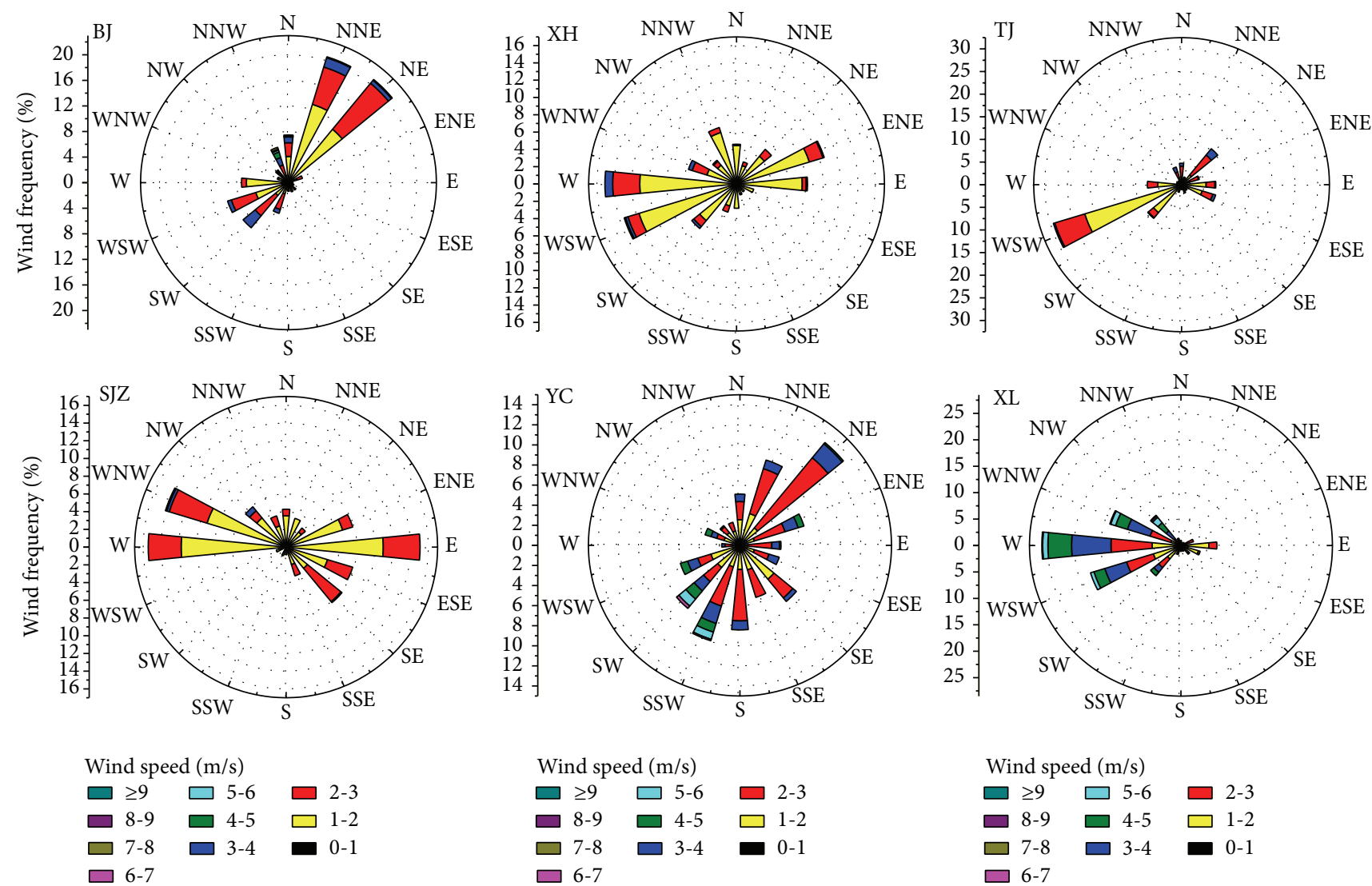

(a)
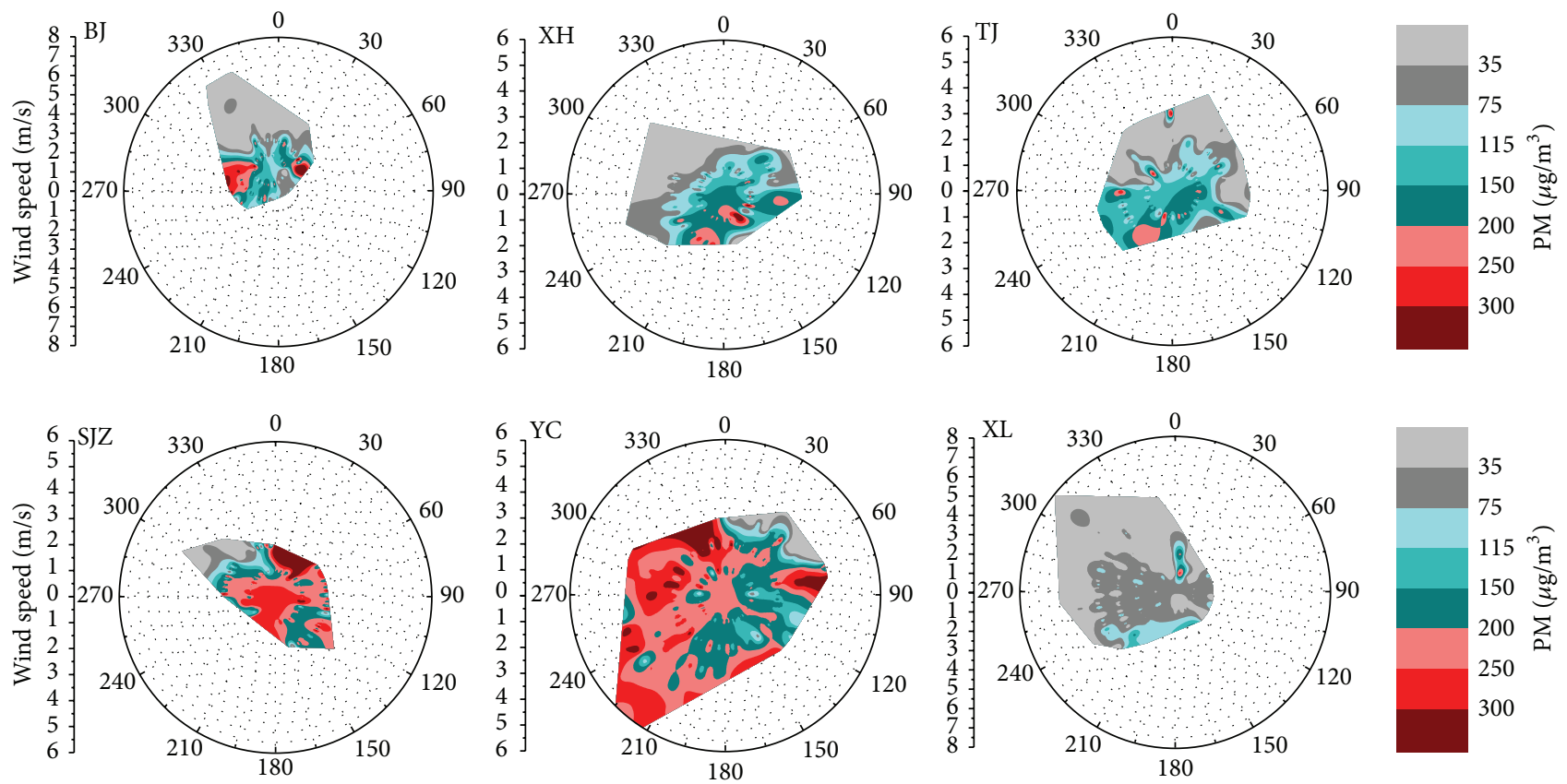

(b)

FIGURE 8: Maps of (a) wind roses and (b) relationships between hourly average $\mathrm{PM}_{2.5}$ concentration and wind speed. 


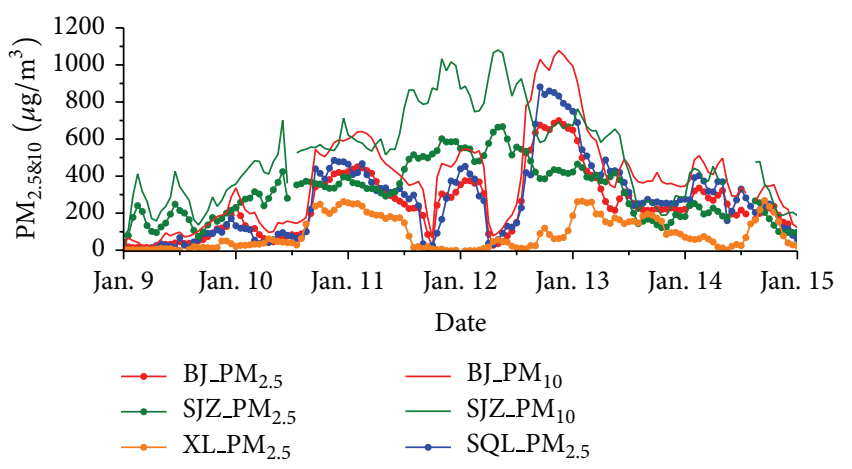

(a)

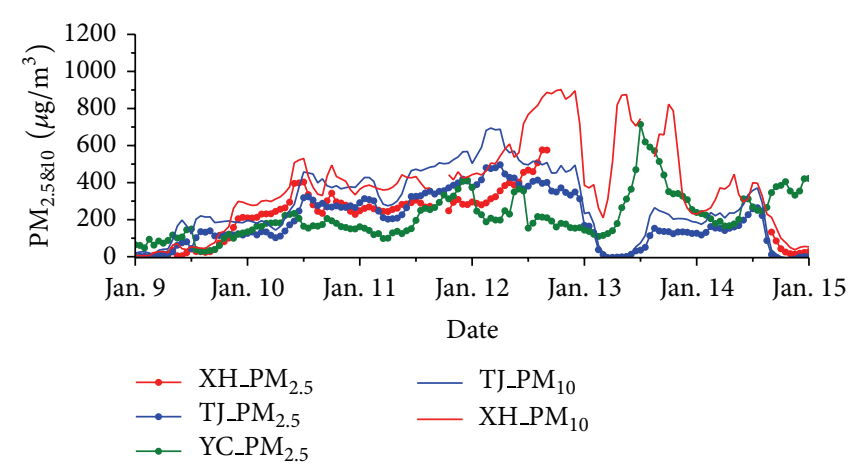

(b)

FIGURE 9: Variation of hourly average concentrations of $\mathrm{PM}_{2.5}$ and $\mathrm{PM}_{10}$ for different sites in the BTH region from January 9 to 14.

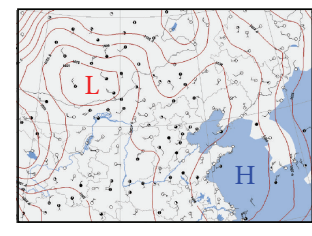

(a)

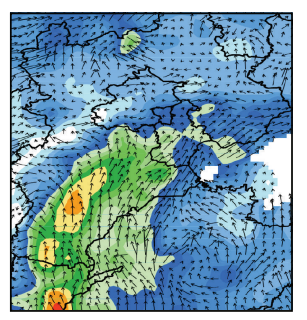

(f)

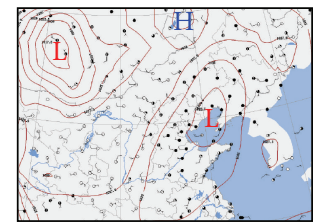

(b)

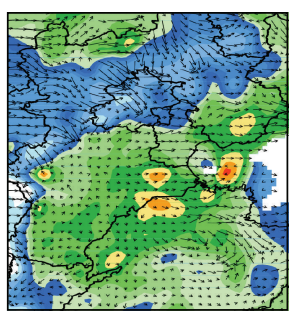

(g)

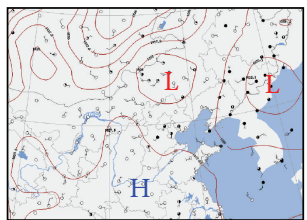

(c)

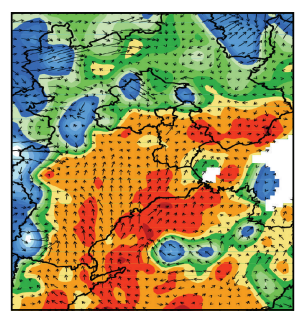

(h)

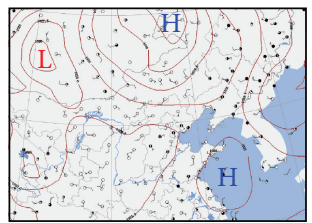

(d)

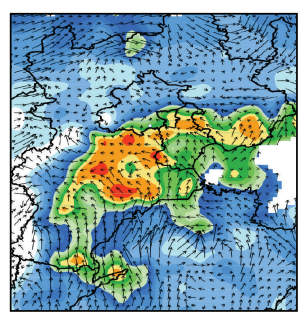

(i)

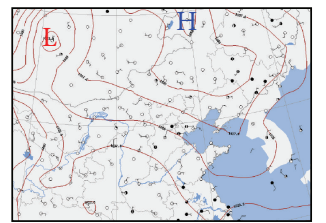

(e)

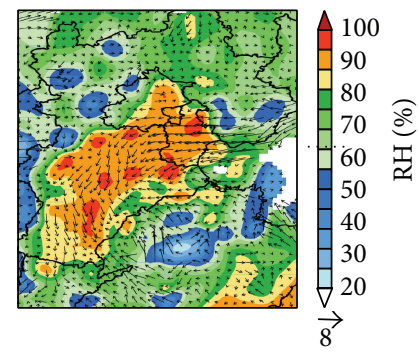

(j)

Figure 10: Synoptic maps at (a) 14:00 LST 10 January, (b) 14:00 LST 11 January, (c) 02:00 LST 12 January, (d) 14:00 LST 12 January, and (e) 02:00 LST 13 January; wind fields and humidity fields (shadings) at (f) 14:00 LST 10 January, (g) 17:00 LST 11 January, (h) 08:00 LST 12 January, (i) 14:00 LST 12 January, and (j) 02:00 LST 13 January.

wind (Figure 10(j)), mainly because of the urban heating effect under the weak pressure field. In addition, because the southeasterly winds transported warm humid air from the Bohai Sea, high humidity facilitated the hygroscopic growth of aerosols; as a result, severe low-visibility events ensued.

The vertical wind profile (Figure 11) revealed very weak horizontal and vertical wind speeds from 14:00 LST on the 12th to 02:00 LST on the 13th in the Beijing urban region compared with those in the Tianjin suburban region. Moreover, two layers above and below $500 \mathrm{~m}$ were distinguishable; therefore, the mixed layer heights were approximately less than $500 \mathrm{~m}$. Figure 12 shows the thickness of the inversion layer $(600-800 \mathrm{~m})$, the temperature range $\left(5-7^{\circ} \mathrm{C}\right)$, and the high humidity forcing below $500 \mathrm{~m}$ on 12 January. Thus, recirculation and regional transport, along with the poorest diffusion conditions and favorable secondary transformation conditions under high emissions and the hygroscopic growth of aerosols, led to the explosive growth and the record high hourly average concentration of $\mathrm{PM}_{2.5}$ in Beijing.

\section{Conclusions}

Haze pollution in winter over the Beijing-Tianjin-Hebei (BTH) region has become worse in recent decades. The most serious events occurred in January 2013, with a monthly regional average $\mathrm{PM}_{2.5}$ value of $\sim 145 \mu \mathrm{g} / \mathrm{m}^{3}$ and a visibility of $\sim 8.3 \mathrm{~km}$, which were most likely due to unfavorable meteorology, rather than an abrupt increase in emissions. The interannual variation in the mean visibility during haze days showed a significant decrease, which indicated that the primary type of haze has changed from slight haze $(5-10 \mathrm{~km})$ to severe or serious haze $(<5 \mathrm{~km})$ since the beginning of the $1990 \mathrm{~s}$ due to unfavorable diffusion conditions (weak surface winds and high humidity) combined with high primary-pollutant emissions. The characteristics of the surface meteorological variables during moderate and severe haze pollution episodes in the $\mathrm{BTH}$ region are as follows: weaker pressure, higher temperature, particularly in the plains region, higher relative humidity, weak winds $(1.7 \sim 2.1 \mathrm{~m} / \mathrm{s})$, fewer sunshine hours, 


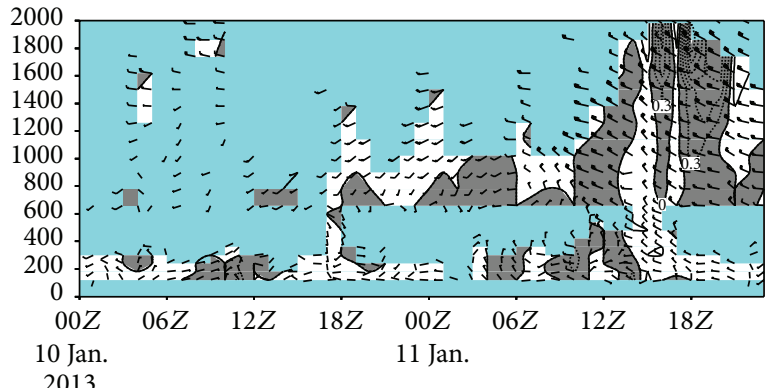

(a)

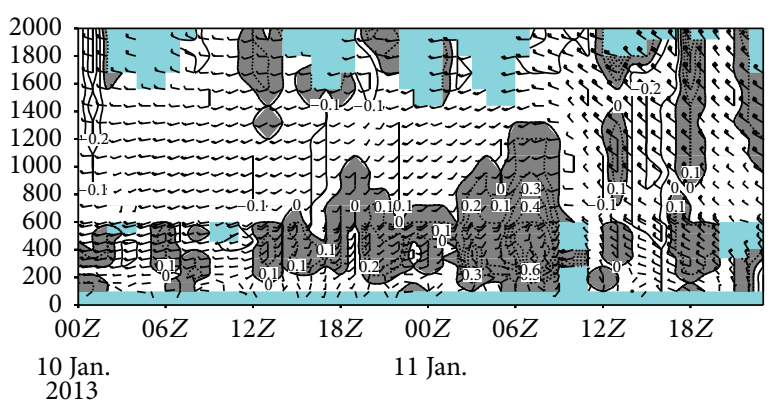

(c)

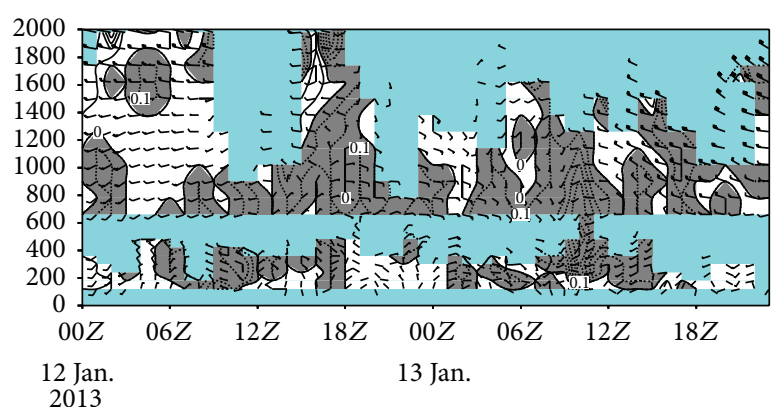

(b)

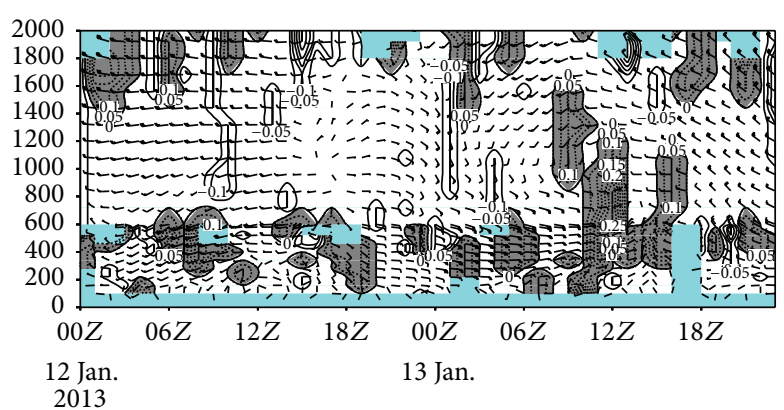

(d)

Figure 11: Wind profile (horizontal vector wind and vertical wind speed (unit: $\mathrm{m} / \mathrm{s})$ ) in Beijing ((a) and (b)) and Tianjin ((c) and (d)) from January 10 to 13 . The shaded map is vertical wind speed, white represents ascending motion with speed $<0 \mathrm{~m} / \mathrm{s}$, and gray represents descending motion with speed $>0 \mathrm{~m} / \mathrm{s}$.

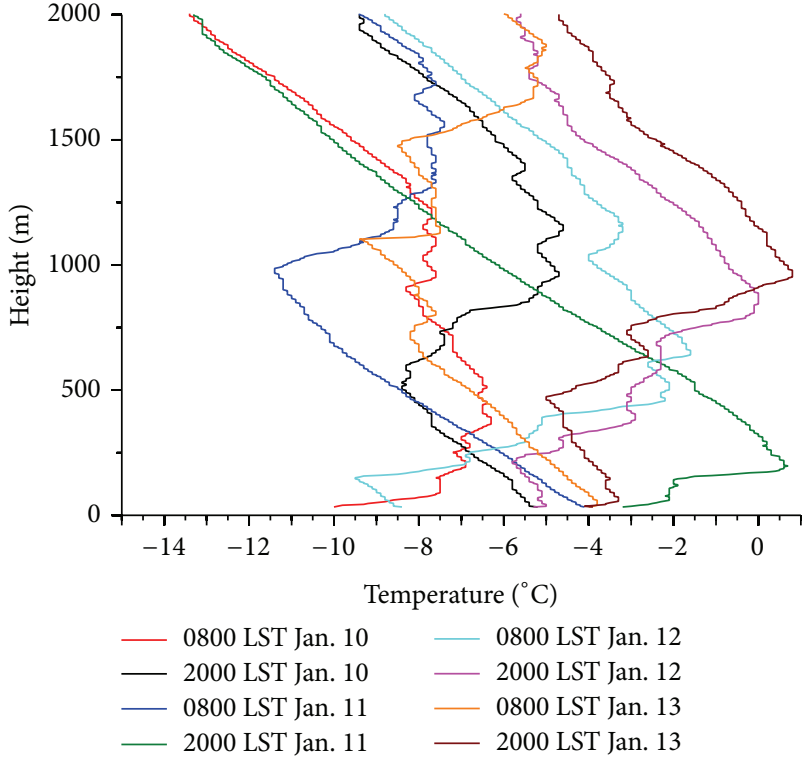

(a)

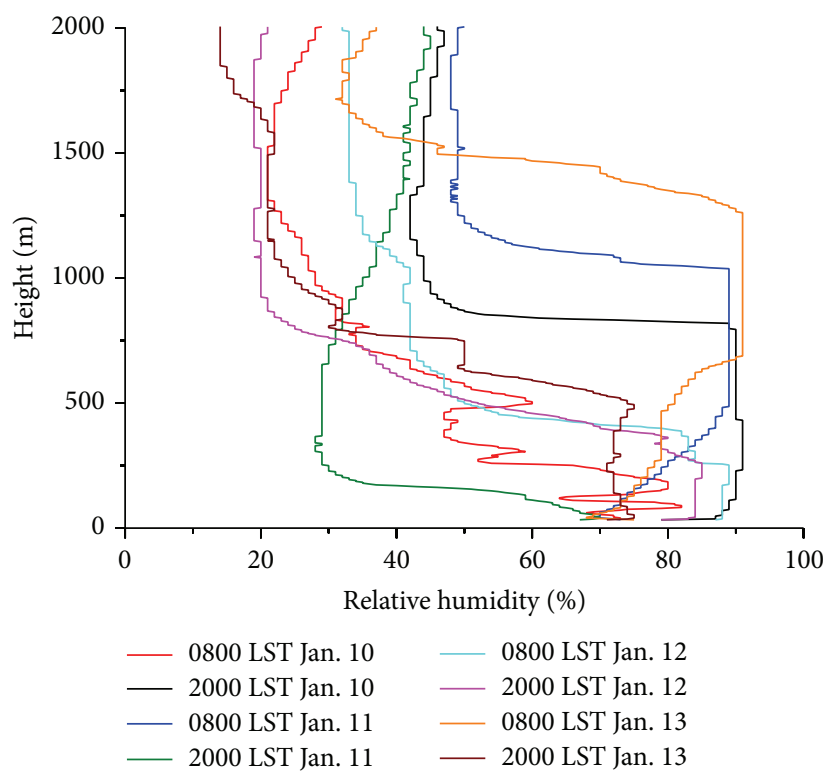

(b)

FIGURE 12: Profiles of temperature and humidity over different periods during 10th 13th January 2013, in Beijing.

and lower visibility. Orographic wind convergence zones resulted in the pollution accumulation in the piedmont plain and restrained the diffusion of pollutions; as a result, severe regional haze pollution developed. Recirculation and regional transport, along with the poorest diffusion conditions and favorable secondary transformation conditions under high emissions and the hygroscopic growth of aerosols, led to the explosive growth and the highest hourly average concentration of $\mathrm{PM}_{2.5}$ in Beijing. Considering that decreasing wind speeds and weakened southerly winds resulted in more stable 
atmospheric conditions and weaker dispersion abilities, an effort should be made to control emissions and prevent haze events.

\section{Conflict of Interests}

The authors declare that there is no conflict of interests regarding the publication of this paper.

\section{Acknowledgments}

This work was supported by National Natural Science Foundation of China (nos. 41230642 and 41175107) and the CAS Strategic Priority Research Program Grant (no. XDB05020203). The authors thank Hu Bo, Guiqian Tang, Yue Wang, Yang Yang, Na Chao, and Yangchun Yu for working for aerosol measures. They acknowledge National Meteorological Information Center, NOAA's National Climatic Data Center (NCDC), National Climate Center, and MODIS team for the data used in their work.

\section{References}

[1] M. Shao, X. Tang, Y. Zhang, and W. Li, "City clusters in China: air and surface water pollution," Frontiers in Ecology and the Environment, vol. 4, no. 7, pp. 353-361, 2006.

[2] G. Fu, W. Xu, R. Rong, J. Li, and C. Zhao, "The distribution and trends of fog and haze in the North China Plain over the past 30 years," Atmospheric Chemistry and Physics Discussions, vol. 14, no. 11, pp. 16123-16149, 2014.

[3] National Bureau of Statistics of China, China Statistical Yearbook 2012, China Statistics Press, 2012.

[4] J. Zhang, Z. Ouyang, H. Miao, and X. Wang, "Ambient air quality trends and driving factor analysis in Beijing, 1983-2007," Journal of Environmental Sciences, vol. 23, no. 12, pp. 2019-2028, 2011.

[5] P. Zhao, X. Zhang, X. Xu, and X. Zhao, "Long-term visibility trends and characteristics in the region of Beijing, Tianjin, and Hebei, China," Atmospheric Research, vol. 101, no. 3, pp. 711-718, 2011.

[6] Y. Wang, L. Yao, L. Wang et al., "Mechanism for the formation of the January 2013 heavy haze pollution episode over central and eastern China," Science China Earth Sciences, vol. 57, no. 1, pp. 14-25, 2014.

[7] D. Ji, Y. Wang, L. Wang et al., "Analysis of heavy pollution episodes in selected cities of northern China," Atmospheric Environment, vol. 50, pp. 338-348, 2012.

[8] X. Zhuang, Y. Wang, H. He et al., "Haze insights and mitigation in China: an overview," Journal of Environmental Sciences, vol. 26, no. 1, pp. 2-12, 2014.

[9] X. Zhao, X. Zhang, X. Xu, J. Xu, W. Meng, and W. Pu, "Seasonal and diurnal variations of ambient PM2.5 concentration in urban and rural environments in Beijing," Atmospheric Environment, vol. 43, no. 18, pp. 2893-2900, 2009.

[10] Z. Li, C. Li, H. Chen et al., "East Asian Studies of Tropospheric Aerosols and their Impact on Regional Climate (EAST-AIRC): an overview," Journal of Geophysical Research D: Atmospheres, vol. 116, no. 4, Article ID D00K34, 2011.

[11] P. Li, J. Xin, Y. Wang et al., "The acute effects of fine particles on respiratory mortality and morbidity in Beijing, 2004-2009,"
Environmental Science and Pollution Research, vol. 20, no. 9, pp. 6433-6444, 2013.

[12] B. Zhao, P. Wang, J. Z. Ma, S. Zhu, A. Pozzer, and W. Li, "A high-resolution emission inventory of primary pollutants for the Huabei region, China," Atmospheric Chemistry and Physics, vol. 12, no. 1, pp. 481-501, 2012.

[13] I. C. Ziomas, D. Melas, C. S. Zerefos, A. F. Bais, and A. G. Paliatsos, "Forecasting peak pollutant levels from meteorological variables," Atmospheric Environment, vol. 29, no. 24, pp. 37033711, 1995.

[14] J. H. Seinfeld and S. N. Pandis, Atmospheric Chemistry and Physics: From Air Pollution to Climate Change, John Wiley \& Sons, New York, NY, USA, 1998.

[15] M. Chin, "Atmospheric science: dirtier air from a weaker monsoon," Nature Geoscience, vol. 5, no. 7, pp. 449-450, 2012.

[16] J. Zhu, H. Liao, and J. Li, "Increases in aerosol concentrations over eastern China due to the decadal-scale weakening of the East Asian summer monsoon," Geophysical Research Letters, vol. 39, no. 9, Article ID L09809, 2012.

[17] Z. H. Chen, S. Y. Cheng, J. B. Li, X. R. Guo, W. H. Wang, and D. S. Chen, "Relationship between atmospheric pollution processes and synoptic pressure patterns in northern China," Atmospheric Environment, vol. 42, no. 24, pp. 6078-6087, 2008.

[18] Y. Sun, T. Song, G. Tang, and Y. Wang, “The vertical distribution of PM2.5 and boundary-layer structure during summer haze in Beijing," Atmospheric Environment, vol. 74, pp. 413-421, 2013.

[19] D. Ji, L. Li, Y. Wang et al., “The heaviest particulate air-pollution episodes occurred in northern China in January, 2013: insights gained from observation," Atmospheric Environment, vol. 92, pp. 546-556, 2014.

[20] D. G. Streets, J. S. Fu, C. J. Jang et al., "Air quality during the 2008 Beijing Olympic Games," Atmospheric Environment, vol. 41, no. 3, pp. 480-492, 2007.

[21] X. Zhao, P. Zhao, J. Xu et al., "Analysis of a winter regional haze event and its formation mechanism in the North China Plain," Atmospheric Chemistry and Physics, vol. 13, no. 11, pp. 56855696, 2013.

[22] M. Tao, L. Chen, L. Su, and J. Tao, "Satellite observation of regional haze pollution over the North China Plain," Journal of Geophysical Research D: Atmospheres, vol. 117, no. 12, Article ID D12203, 2012.

[23] J. Y. Xin, Y. S. Wang, G. Q. Tang et al., "Variability and reduction of atmospheric pollutants in Beijing and its surrounding area during the Beijing 2008 Olympic Games," Chinese Science Bulletin, vol. 55, no. 18, pp. 1937-1944, 2010.

[24] H. Wang, S.-C. Tan, Y. Wang et al., "A multisource observation study of the severe prolonged regional haze episode over eastern China in January 2013," Atmospheric Environment, vol. 89, pp. 807-815, 2014.

[25] H. He, Y. Wang, Q. Ma et al., "Mineral dust and NOx promote the conversion of $\mathrm{SO}_{2}$ to sulfate in heavy pollution days," Scientific Reports, vol. 4, article 4172, 2014.

[26] Y. L. Sun, Q. Jiang, Z. F. Wang et al., "Investigation of the sources and evolution processes of severe haze pollution in Beijing in January 2013," Journal of Geophysical Research-Atmospheres, vol. 119, no. 7, pp. 4380-4398, 2013.

[27] G. J. Zheng, F. K. Duan, Y. L. Ma et al., "Exploring the severe winter haze in Beijing," Atmospheric Chemistry and Physics, vol. 14, no. 12, pp. 17907-17942, 2014.

[28] R. H. Zhang, Q. Li, and R. N. Zhang, "Meteorological conditions for the persistent severe fog and haze event over eastern China 
in January 2013," Science China Earth Sciences, vol. 57, no. 1, pp. 26-35, 2014.

[29] P. Zhao, X. Zhang, and X. Xu, "Comparison between two methods of distinguishing haze days with daily mean and 14 oclock meteorological data," Acta Scientiae Circumstantiae, vol. 31, no. 4, pp. 704-708, 2011.

[30] Y. J. Kaufman, D. Tanré, L. A. Remer, E. F. Vermote, A. Chu, and B. N. Holben, "Operational remote sensing of tropospheric aerosol over land from EOS moderate resolution imaging spectroradiometer," Journal of Geophysical Research D: Atmospheres, vol. 102, no. 14, pp. 17051-17067, 1997.

[31] D. Tanré, Y. J. Kaufman, M. Herman, and S. Mattoo, "Remote sensing of aerosol properties over oceans using the MODIS/EOS spectral radiances," Journal of Geophysical Research D: Atmospheres, vol. 102, no. 14, pp. 16971-16988, 1997.

[32] L. A. Remer, Y. J. Kaufman, D. Tanré et al., "The MODIS aerosol algorithm, products, and validation," Journal of the Atmospheric Sciences, vol. 62, no. 4, pp. 947-973, 2005.

[33] L. A. Remer, D. Tanré, and Y. J. Kaufman, "Algorithm for remote sensing of tropospheric aerosol form MODIS: collection 5," 2006, http://modis-atmos.gsfc.nasa.gov/MOD04_L2/.

[34] R. C. Levy, L. A. Remer, S. Mattoo, E. F. Vermote, and Y. J. Kaufman, "Second-generation operational algorithm: Retrieval of aerosol properties over land from inversion of Moderate Resolution Imaging Spectroradiometer spectral reflectance," Journal of Geophysical Research D: Atmospheres, vol. 112, no. 13, Article ID D13211, 2007.

[35] N. C. Hsu, S.-C. Tsay, M. D. King, and J. R. Herman, "Aerosol properties over bright-reflecting source regions," IEEE Transactions on Geoscience and Remote Sensing, vol. 42, no. 3, pp. 557569, 2004.

[36] H. Guo, M. Xu, and Q. Hu, "Changes in near-surface wind speed in China: 1969-2005," International Journal of Climatology, vol. 31, no. 3, pp. 349-358, 2011.

[37] Y. H. Yang, N. Zhao, X. H. Hao, and C. Q. Li, "Decreasing trend of sunshine hours and related driving forces in North China," Theoretical and Applied Climatology, vol. 97, no. 1-2, pp. 91-98, 2009. 

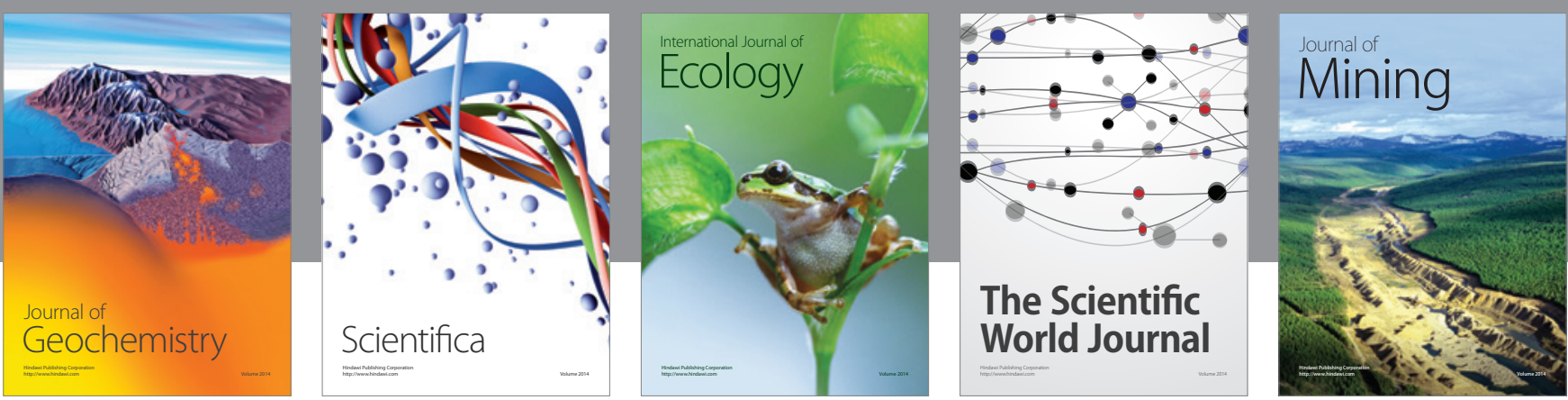

The Scientific World Journal
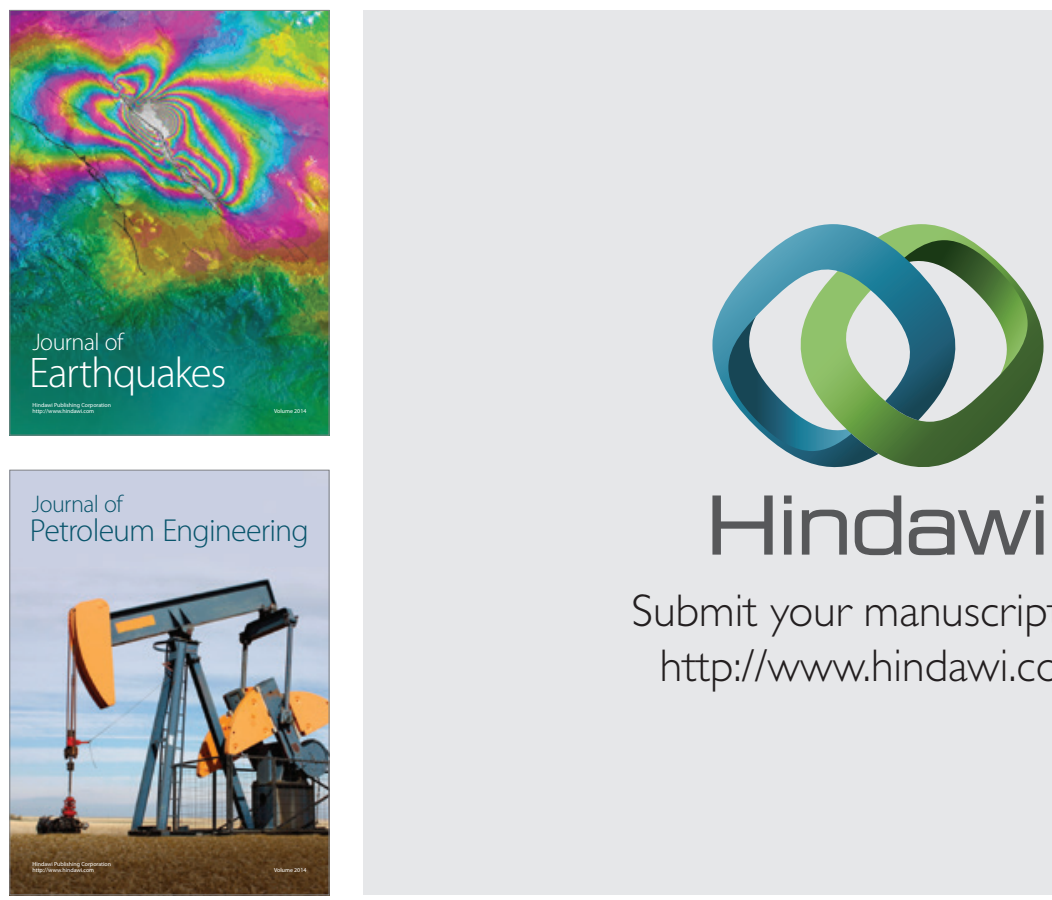

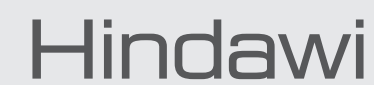

Submit your manuscripts at

http://www.hindawi.com
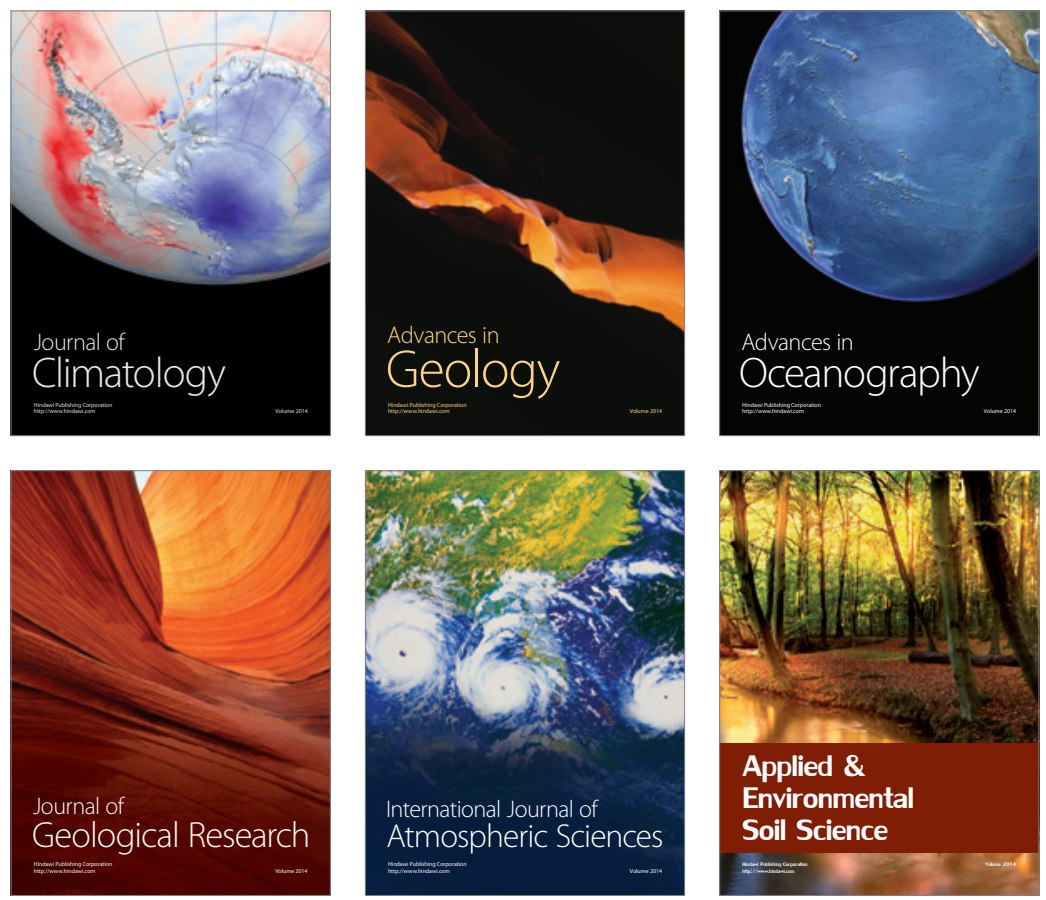
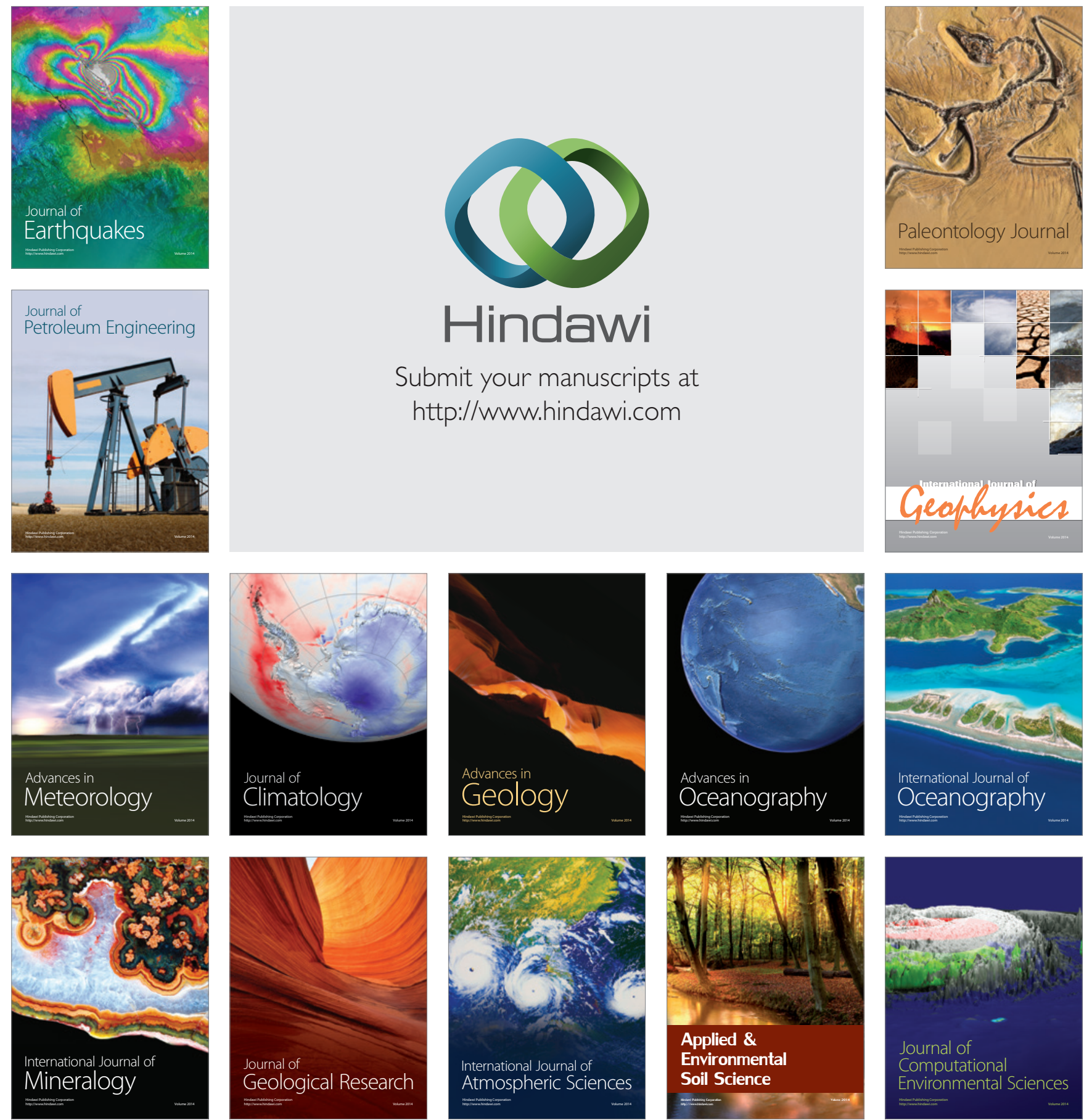